\title{
A Non-Cooperative Framework for Coordinating a Neighborhood of Distributed Prosumers
}

Azar, Armin Ghasem; Nazaripouya, Hamidreza; Khaki, Behnam; Chu, Chi-Cheng; Gadh, Rajit; Jacobsen, Rune Hylsberg

Published in:

I E E E Transactions on Industrial Informatics

Link to article, DOI:

10.1109/TII.2018.2867748

Publication date:

2018

Document Version

Peer reviewed version

Link back to DTU Orbit

Citation (APA):

Azar, A. G., Nazaripouya, H., Khaki, B., Chu, C-C., Gadh, R., \& Jacobsen, R. H. (2018). A Non-Cooperative Framework for Coordinating a Neighborhood of Distributed Prosumers. I E E E Transactions on Industrial Informatics, 15(5), 2523-2534. https://doi.org/10.1109/TII.2018.2867748

\section{General rights}

Copyright and moral rights for the publications made accessible in the public portal are retained by the authors and/or other copyright owners and it is a condition of accessing publications that users recognise and abide by the legal requirements associated with these rights.

- Users may download and print one copy of any publication from the public portal for the purpose of private study or research.

- You may not further distribute the material or use it for any profit-making activity or commercial gain

- You may freely distribute the URL identifying the publication in the public portal 


\title{
A Non-Cooperative Framework for Coordinating a Neighborhood of Distributed Prosumers
}

\author{
Armin Ghasem Azar, Hamidreza Nazaripouya, Members, IEEE, Behnam Khaki, Student Member, IEEE, \\ Chi-Cheng Chu, Rajit Gadh, Member, IEEE, and Rune Hylsberg Jacobsen, Senior Member, IEEE
}

\begin{abstract}
This paper introduces a scalable framework to coordinate the net load scheduling, sharing, and matching in a neighborhood of residential prosumers connected to the grid. As the prosumers are equipped with smart appliances, photovoltaic panels, and battery energy storage systems, they take advantage of their consumption, generation, and storage flexibilities to exchange energy with neighboring prosumers through negotiating on the amount of energy and its price with an aggregator. The proposed framework comprises two separate multi-objective mixed integer nonlinear programming optimization models for prosumers and the aggregator. Prosumers' objective is to maximize the comfort level and minimize the electricity cost at each instant of time, while aggregator intends to maximize its profit and minimize the grid burden by matching prosumers' supply and demand. The evolutionary Non-dominated Sorting Genetic Algorithm-III (NSGA-III) is employed to generate a set of feasible non-dominated solutions to the optimization problem of each individual prosumer and the aggregator. As a bilateral negotiation between each prosumer and the aggregator results in significant computational and communication overhead, a virtual power plant is introduced as an intermediator on behalf of all prosumers to proceed the negotiation with the aggregator in a privacy-preserving non-cooperative environment, where no private information is shared. Hence, an automated negotiation approach is embedded in the framework, which enables the negotiators to reactively negotiate on concurrent power and price using private utility functions and preferences. To converge to an acceptable agreement, the negotiation approach follows an alternating-offer production protocol and a reactive utility value concession strategy. The effectiveness of the framework is evaluated by several economic and environmental assessment metrics through a variety of numerical simulations.
\end{abstract}

Index Terms-Distributed coordination, energy negotiation, multi-objective optimization, pricing, prosumers, smart grid.

\section{NOMENCLATURE}

\section{Constants}

$a$

\section{An appliance}

Manuscript received December 11, 2017; revised March 31, 2018 and July 30, 2018; accepted August 16, 2018. Date of publication XXX; date of current version XXX. This work has been funded by European Union FP7 program under grant agreement $\mathrm{n}^{\circ} 619560$ (SEMIAH). Paper no. TII-18-0786. (Corresponding author: Armin Ghasem Azar).

A. G. Azar was with Department of Engineering, Aarhus University, Denmark, and is now with Department of Applied Mathematics and Computer Science at Technical University of Denmark (DTU), Denmark, email: agaz@dtu.dk.

H. Nazaripouya is with Winston Chung Global Energy Center, University of California, Riverside (UCR), USA, email: hamidn@ucr.edu.

B. Khaki, C. Chu, and R. Gadh are with Department of Mechanical Engineering, University of California Los Angeles (UCLA), USA, emails: \{behnamkhaki, peterchu, gadh\}@ucla.edu.

R. H. Jacobsen is with Department of Engineering, Aarhus University, Denmark, e-mail: rhj@eng.au.dk.

Digital Object Identifier XXX

\author{
$\beta, \theta, \alpha \quad$ Desired operating end time, flexibility, and start \\ time of an appliance \\ $n \quad$ Number of appliances \\ $B^{\text {cap }} \quad$ BESS capacity $(\mathrm{kWh})$ \\ $\delta \quad$ Negotiation convergence tolerance \\ $\epsilon \quad$ Decay rate controller for the time-dependent con- \\ cession values \\ $\mathcal{T} \quad$ Number of negotiation iterations \\ $\rho \quad$ A prosumer \\ $m \quad$ Number of prosumers \\ $K \quad$ Number of solutions to the optimization problem \\ $P V^{\text {cap }} \quad$ Power generation capacity of a PV $(\mathrm{kW})$ \\ $\Delta t \quad$ Time interval resolution \\ $T \quad$ Number of time intervals \\ $\psi \quad$ Utility function \\ $B^{\bar{c}(\bar{d})} \quad$ Maximum (dis)charging power of a BESS $(\mathrm{kW})$
}

Indexes

$\widetilde{k}, k, j, \iota, i$ Behavior matrix, behavior pair, appliance, negotiation iteration, prosumer, and time interval

Sets

$\mathcal{A P}, \mathcal{P} \quad$ Set of appliances, and prosumers

lp Load profile of an appliance

$\mathbb{R}, \mathbb{B}, \mathbb{N} \quad$ Real, Binary, and Natural numbers

Variables

$\mathscr{Z}(t) \quad$ The zone of agreement in the negotiation

$\tau(t) \quad$ Load demand of an appliance (kW)

$B^{e}(t) \quad$ Amount of energy stored in a BESS (kWh)

$B^{c(d)}(t) \quad$ (Dis)Charging power of a BESS $(\mathrm{kW})$

$v^{c(d)}(t) \quad$ Binary (dis)charging status of a BESS

$\widetilde{\mathcal{B M}}(t) \quad$ A behavior matrix

$\mathcal{B P}(t) \quad$ A behavior pair

dec $(t) \quad$ Binary decision variable of operating an appliance

$\omega(\iota) \quad$ Reactive concession value

$\Pi(\iota) \quad$ Desired utility value

$p(t) \quad$ Electricity price $(\$ / \mathrm{kWh})$

$Z(t) \quad$ Set of feasible desired offer packages

$\bar{Z}(\iota) \quad$ Subset of feasible desired offer packages

flex $(t) \quad$ Binary flexibility status of an appliance

$\sigma(\iota) \quad$ Offer package

$\aleph(t), \widetilde{\aleph}(t)$ Power exchanged between a prosumer/aggregator and the grid $(\mathrm{kW})$

$\varphi(\iota) \quad$ Offer package projection weight

$P V^{g}(t) \quad$ PV generation $(\mathrm{kW})$

$\mathcal{S I}(t) \quad$ Satisfaction index

$\varsigma(\iota) \quad$ Time-dependent concession value

$\chi(\iota) \quad$ Weighted offer package 


\section{INTRODUCTION}

\section{A. Motivation and Problem Statement}

O WING to advanced communication, data processing, and control systems, the smart grid from a global perspective is a promising technology for increasing the grid integration of Renewable Energy Sources (RESs), such as Photovoltaics (PVs), as well as Battery Energy Storage Systems (BESSs) [1]. Such integration leads to the enhancement of grid services, e.g., peak demand reduction, and, therefore, provides system operators with a capability of an efficient and optimal management of the power grid. Although electricity prosumers are also benefiting from the smart grid technology by flexibility utilization and electricity bill reduction as a consequence of responding to demand response incentives, they are not involved directly in the benefits of this technology [2]. In other words, prosumers, without having collaboration with aggregators, do not have enough authority, in terms of flexibility, to be able to individually participate in a dynamic bilateral decision-making procedure, which could provide them with the opportunity to influence the amount of electricity they receive (inject) from (to) the grid as well as the electricity price [3].

Realizing such an interactive and fair bilateral trade is challenging due to lack of: i) a scalable framework, in terms of the number of consumers, to coordinate the scheduling, sharing, and matching tasks, ii) a practical real-time decision-making model to consider the dynamic behavior of the prosumers' load demands and RESs' generation, and iii) an efficient negotiation approach to enable the coordination in a privacy-preserving environment, in which neither prosumers nor aggregators (or system operators) share their sensitive information, such as flexibility information and objective functions, with each other.

\section{B. Related Work}

Efforts have been devoted to solving the coordination problem in two interrelated zones: i) transmission-distribution system operators (by e.g., proposing decentralized decisionmaking algorithms for optimal power flow implementation while respecting the operators' autonomy and information privacy [4]), and ii) scheduling, sharing, and matching between a set of end users. The latter has recently received much attention, where the proposed solutions in the literature fall into two categories, i.e., centralized and distributed. In the former, a centralized coordinator receives load demand scenarios accompanied with available flexibility of prosumers and attempts to match supply and demand according to peerto-peer energy sharing model with price-based demand response. Such approaches comprise a single- or multi-objective optimization model to reduce prosumers' electricity bills, flatten the aggregated peak demand, or maximize comfort level [5]-[11]. The main issues with the centralized approaches include having no guarantee in balancing demand and supply, nonscalability, unfair energy trading pricing, and prosumers' privacy violation. Distributed approaches, which attempt to address the issues raised for centralized approaches, propose distributed energy management systems based on model predictive control methodologies under a dynamic pricing system. [12]-[20] are some examples of proposing day-ahead or real-time demand-side management systems for peer-to-peer exchanging of electricity between prosumers, equipped with PVs and BESSs, where the pricing and trading contracts are handled by submission-based, iterative or (non-)cooperative game theory mechanisms. Even though these mechanisms are able to achieve an exact demand supply balance based on a dynamic pricing scheme, they should, however, access to a complete list of preferences, full information of aggregated consumption/generation profiles, which violates privacy. Moreover, no negotiation takes place between prosumers and excess energy is injected to the grid at a fixed price rate defined by the grid rather than prosumers.

\section{Contributions and Organization of the Paper}

This paper, to address the above-mentioned challenges and fulfills the existing gaps, makes the following contributions: 1) We propose a scalable non-cooperative framework to coordinate the scheduling, sharing, and matching tasks of prosumers and the aggregator. Its principal advantageous is that the trading amount, which depends on prosumers' realtime available flexibility, and trading price, which is subject to considerable fluctuations in the market, are co-decided by all the prosumers. This implies that each prosumer has an equal privilege and is able to switch its interaction mode (buyer/seller) at any time instant. Fig. 1 shows an overview of the proposed framework.

2) We develop two practical Multi-Objective Mixed Integer Nonlinear Programming (MO-MINLP) optimization models for prosumers and the aggregator enabling them to negotiate their energy in the framework. They are tailored the framework in such a way that help prosumers and the aggregator quantify their possible social and financial benefits throughout the negotiation. The first model assists prosumers in scheduling their appliances and sharing/satisfying their surplus/demand with/through the grid. It confronts the conflicting objectives of maximizing the comfort level and benefit considering the available flexibility of each prosumer [10], [21]. The second model serves the aggregator to simultaneously maximize the profit and minimize the grid purchase [22]. It enables the aggregator to match supply and demand in the grid considering prosumers' interaction mode. We employ the Non-dominated Sorting Genetic Algorithm-III (NSGA-III) [23] to help prosumers and the aggregator strategically make trade-offs over non-dominated solutions, where each solution declares the amount of power to sell/buy and the corresponding price.

3) We introduce a bilateral multi-issue negotiation approach incorporated into the framework to enable the aggregator to negotiate with a Virtual Power Plant (VPP), as an intermediator on behalf of prosumers. An alternative solution, though with high overheads, is concurrent bilateral negotiations between prosumers and the aggregator. Such approach might not facilitate such a complicated decision-making process, since: i) computationally, it would be a high-burden mechanism to reach an overall agreement during the negotiation procedures, and ii) infeasible aggregated matching solutions might be obtained when the amount of power traded by each prosumer changes over the negotiation process. Of particular interest 


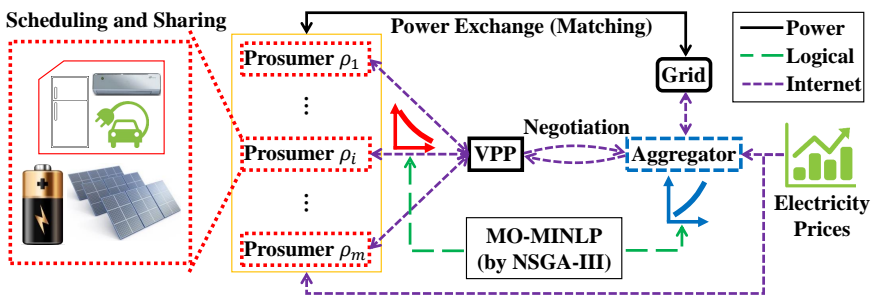

Fig. 1. System model of the proposed framework.

is that the proposed negotiation approach is conducted in a non-cooperative environment [24], where no private information (i.e., flexibility information and utility functions) is shared between the negotiators. This approach is based on an alternating-offer production protocol and a novel reactive utility value concession strategy guaranteeing convergence to a unanimous feasible agreement. Negotiators own nonlinear, continuous, and strictly concave utility functions. They start the negotiation with an offer package (made with nondominated solutions) providing the highest possible utility value. They reactively concede to their pre-defined reservation offer packages (the degraded but still feasible) within a predefined number of negotiation iterations. They neither propose nor accept any offer package with utility values lower than their reservation utility values. To help negotiators identify the most beneficial offer package, a novel evaluation metric, named satisfaction index, is presented to quantify each offer package according to the amount of flexibility used and the profitability of the price offered.

The rest of paper is structured as follows: Section II presents the system architecture of the framework; Section III introduces the NSGA-III for solving the MO-MINLP problems; Section IV describes the negotiation approach; Section V provides the simulation setup and discusses the results; and, Section VI concludes the paper and outlines the future work.

\section{SySTEM ARCHITECTURE}

This paper considers a smart grid including $m \in \mathbb{N}$ prosumers $\mathcal{P}=\left\{\rho_{1}, \ldots, \rho_{i}, \ldots, \rho_{m}\right\}$, which communicate with an aggregator through a VPP (modeled in Section IV-A).

\section{A. Prosumers}

Fig. 2 shows power actions of prosumer $\rho_{i}$ at time interval $t \in \mathbb{N}$. Let $\mathcal{A P} \mathcal{P}_{i}$ be the set of appliances of prosumer $\rho_{i}$. Appliance $a_{j, i} \in \mathcal{A P}_{i}, 1 \leq j \leq n_{i} \in \mathbb{N}$ is either nonshiftable (e.g., refrigerator) or shiftable (e.g., electric vehicle). Shiftability feature provides the prosumer with a flexibility degree to interrupt the operation of appliances [10], [25]. Let

$$
\begin{aligned}
& \sum_{t=\alpha_{j, i}}^{\beta_{j, i}} \tau_{j, i}(t) \cdot \operatorname{dec}_{j, i}(t)=\left|l p_{j, i}\right|, \\
& \sum_{j=1}^{n_{i}} \tau_{j, i}(t) \cdot \operatorname{dec}_{j, i}(t)=\aleph_{i}^{\mathrm{P} 2 \mathrm{~L}}(t)+\aleph_{i}^{\mathrm{B} 2 \mathrm{~L}}(t)+\aleph_{i}^{\mathrm{G} 2 \mathrm{~L}}(t), \\
& \begin{cases}\operatorname{dec}_{j, i}(t) \in\{0,1\} & \text { flex }_{j, i}(t)=1, \\
\operatorname{dec}_{j, i}(t)=1 & \text { otherwise, }\end{cases}
\end{aligned}
$$

$$
\operatorname{flex}_{j, i}(t)= \begin{cases}0 & \left(\beta_{j, i}-\alpha_{j, i}\right) \leq\left(\theta_{j, i}-t\right), \\ 1 & \text { otherwise, }\end{cases}
$$

where $\alpha_{j, i}, \beta_{j, i} \in \mathbb{Z}_{\geq 0}$ are the "desired operation start" and "normal operation end" times of appliance $a_{j, i}$, following a specific load profile $l p_{j, i}$. Then, $\tau_{j, i}(t) \in \mathbb{R}_{\geq 0}(\mathrm{~kW})$ specifies the amount of power the appliance needs to operate between each two time intervals $t$ and $t+\Delta t$. Note that $\Delta t \in \mathbb{N}$ is the time interval resolution. $\operatorname{dec}_{j, i}(t) \in \mathbb{B}$ is the binary decision variable of the corresponding load. Decision variables for nonshiftable appliances are always one. Eq. (1) ensures that the energy needed for each appliance over a given time horizon is fully satisfied. Eq. (2) states that load demands at each time interval are satisfied through $\aleph_{i}^{\mathrm{P} 2 \mathrm{~L}}(t), \aleph_{i}^{\mathrm{B} 2 \mathrm{~L}}(t), \aleph_{i}^{\mathrm{G} 2 \mathrm{~L}}(t) \in$ $\mathbb{R}_{\geq 0}(\mathrm{~kW})$, denoting the power transferred from the PV, the BESS, and the grid to appliances, respectively. $\operatorname{dec}_{j, i}(t)$, as modeled in (3), is affected by the corresponding binary flexibility status $\operatorname{flex}_{j, i}(t) \in \mathbb{B}$. The status is updated according to the flexibility deadline $\theta_{j, i} \in \mathbb{Z}_{\geq 0}$, which is adjusted by the prosumer, defining for how long the prosumer is flexible in having the appliance's operation finished after its normal end time [26]. Each prosumer is equipped with a locally installed PV system (behind the meter). Let

$$
P V_{i}^{g}(t)=\aleph_{i}^{\mathrm{P} 2 \mathrm{~L}}(t)+\aleph_{i}^{\mathrm{P} 2 \mathrm{~B}}(t)+\aleph_{i}^{\mathrm{P} 2 \mathrm{G}}(t) \leq P V_{i}^{c a p},
$$

where $P V_{i}^{g}(t), P V_{i}^{c a p} \in \mathbb{R}_{\geq 0}(\mathrm{~kW})$ are the amount of power generated by $\mathrm{PV}$ at time interval $t$ and PV's maximum generating capacity, respectively. $\aleph_{i}^{\mathrm{P} 2 \mathrm{~B}}(t), \aleph_{i}^{\mathrm{P} 2 \mathrm{G}}(t) \in \mathbb{R}_{\geq 0}(\mathrm{~kW})$ are the amount of power transferred from the PV into the BESS and the grid, respectively [27]. Demand for electricity changes through the day and does not necessarily match with the PV production. BESSs, by storing the energy during offpeak, utilizing it during peak periods, or selling it to the grid, can alleviate such challenges. Let

$B_{i}^{e}(t+1)=B_{i}^{e}(t)+\left(B_{i}^{c}(t) \cdot v_{i}^{c}(t)-B_{i}^{d}(t) \cdot v_{i}^{d}(t)\right) \cdot \Delta t$,

$$
\begin{aligned}
& B_{i}^{e}(t) \leq B_{i}^{c a p} \\
& B_{i}^{c}(t)=\aleph_{i}^{\mathrm{P} 2 \mathrm{~B}}(t)+\aleph_{i}^{\mathrm{G} 2 \mathrm{~B}}(t) \leq B_{i}^{\bar{c}}, \\
& B_{i}^{d}(t)=\aleph_{i}^{\mathrm{B} 2 \mathrm{G}}(t)+\aleph_{i}^{\mathrm{B} 2 \mathrm{~L}}(t) \leq B_{i}^{\bar{d}}, \\
& v_{i}^{c}(t)+v_{i}^{d}(t) \leq 1,
\end{aligned}
$$

where $B_{i}^{e}(t), B_{i}^{c a p} \in \mathbb{R}_{>0}$ (kWh) are the amount of energy stored in the BESS until time interval $t$ and the BESS capacity, respectively. Notations $B_{i}^{c}(t), B_{i}^{d}(t) \in \mathbb{R}_{\geq 0}(\mathrm{~kW})$ denote the

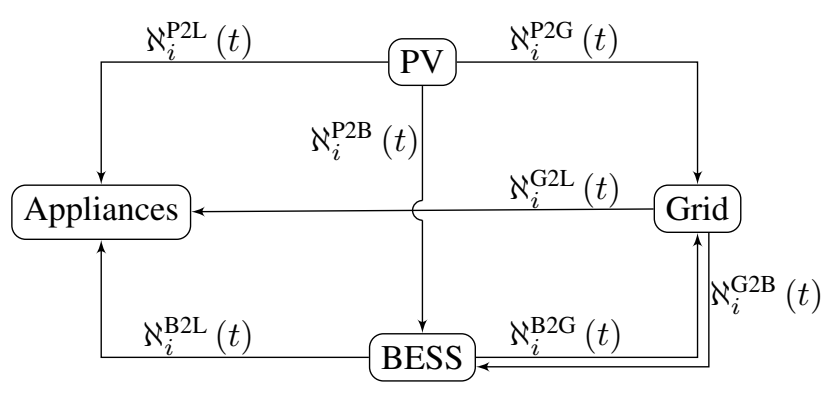

Fig. 2. Model diagram of the power actions of prosumer $\rho_{i}$. 
amount of power the battery is "charged" and "discharged" with, respectively. The operation of the BESS is controlled by $v_{i}^{c}(t), v_{i}^{d}(t) \in \mathbb{B}$, as binary charging and discharging variables respectively. Eq. (10) prevents the BESS from being charged and discharged simultaneously. Thus, the BESS, at each time interval, can either be charged, discharged, or remain silent. Notations $\aleph_{i}^{\mathrm{B} 2 \mathrm{G}}(t), \aleph_{i}^{\mathrm{G} 2 \mathrm{~B}}(t) \in \mathbb{R}_{\geq 0}(\mathrm{~kW})$ denote the amount of power transferred from the BESS to the grid and vice versa, depending on $B_{i}^{\bar{c}}, B_{i}^{\bar{d}} \in \mathbb{R}_{>0}(\mathrm{~kW})$, as maximum possible charging and discharging power, respectively [28].

Thus, the following defines the optimization model, which is applicable to each independent prosumer $\rho_{i} \in \mathcal{P}$ :

$$
\begin{aligned}
& \underset{\left\{\operatorname{dec}_{j, i}(t)\right\}_{j=1}^{n_{i}}, B_{i}^{c}(t)}{\operatorname{maximize}} \sum_{j=1}^{n_{i}} \tau_{j, i}(t) \cdot \operatorname{dec}_{j, i}(t)+B_{i}^{c}(t), \\
& \underset{\aleph_{i}(t), p_{i}(t)}{\operatorname{maximize}} \aleph_{i}(t) \cdot p_{i}(t) \cdot \Delta t,
\end{aligned}
$$

subject to

$$
\begin{aligned}
& (1)-(10), \\
& \underline{\aleph}_{i}(t) \leq \aleph_{i}(t) \leq \bar{\aleph}_{i}(t), \\
& p^{l}(t) \leq p_{i}(t) \leq p^{u}(t), \\
& \aleph_{i}(t)=P V_{i}^{g}(t)-\sum_{j=1}^{n_{i}} \tau_{j, i}(t)-B_{i}^{\bar{c}}, \\
& \bar{\aleph}_{i}(t)=P V_{i}^{g}(t)+B_{i}^{\bar{d}}-\sum_{\quad f l e x} \tau_{j, i}(t)=0, \\
& \forall a_{j, i} \in \mathcal{A} \mathcal{P}_{i} \\
& \aleph_{i}(t)=\aleph_{i}^{\mathrm{B} 2 \mathrm{G}}(t)+\aleph_{i}^{\mathrm{P} 2 \mathrm{G}}(t)-\aleph_{i}^{\mathrm{G} 2 \mathrm{~B}}(t)-\aleph_{i}^{\mathrm{G} 2 \mathrm{~L}}(t),
\end{aligned}
$$

where the prosumer faces a multi-objective optimization problem involving two objective functions solved simultaneously. Eq. (11) aims at maximizing the prosumer's comfort level by satisfying as many load demands as possible and charging its BESS as much as possible. The reason for considering the charging completeness of the BESS [29] in (11) is twofold: i) to allow wide solution-space exploration by making the corresponding objective function continuous. With empty battery, due to the discrete nature of appliances (on and off), the demand profile would also be discrete, and ii) to store energy during low-price and utilize it (to either satisfy load demands or inject it back to the grid) during high-price periods. Eq. (12) intends to maximize the prosumer's profit by selling more power to the grid. These two objectives are in conflict with each other, since trying to inject more power to the grid results in jeopardizing the prosumer's comfort level and vice versa. $\aleph_{i}(t) \in \mathbb{R}(\mathrm{kW})$ is the desired amount of power the prosumer strives to exchange with the grid coupled with a price offer $p_{i}(t) \in \mathbb{R}_{>0}(\$ / \mathrm{kWh})$. This price is selected between $\left[p^{l}(t), p^{u}(t)\right] \in \mathbb{R}_{>0} \quad(\$ / \mathrm{kWh})$ as the minimum and maximum offerable price for trading energy, respectively.

$\underline{\aleph}_{i}(t)$ and $\bar{\aleph}_{i}(t)$ are the optimum values for trading the power, which can maximize the comfort level, and profit, respectively, where $\underline{\aleph}_{i}(t) \leq \aleph_{i}(t) \leq \bar{\aleph}_{i}(t)$. When $\aleph_{i}(t)=$ $\underline{\aleph}_{i}(t)$, all demanding appliances are allowed to operate and the BESS is fully charged. When $\aleph_{i}(t)=\bar{\aleph}_{i}(t)$, the profit is maximized and appliances, with no flexibility $\left(\right.$ flex $\left._{j, i}(t)=0, \forall a_{j, i} \in \mathcal{A} \mathcal{P}_{i}\right)$, are only allowed to operate. The remaining is sold to the grid. Prosumers are not allowed to buy and sell at the same time. Each prosumer at each interval can either be: i) a buyer, i.e., $\underline{\aleph}_{i}(t) \leq \bar{\aleph}_{i}(t)<0$, where $\aleph_{i}^{\mathrm{G} 2 \mathrm{~B}}(t)+\aleph_{i}^{\mathrm{G} 2 \mathrm{~L}}(t)>0$ and $\aleph_{i}^{\mathrm{B} 2 \mathrm{G}}(t)=\aleph_{i}^{\mathrm{P} 2 \mathrm{G}}(t)=0$, ii) a seller, i.e., $0<\underline{\aleph}_{i}(t) \leq \bar{\aleph}_{i}(t)$, where $\aleph_{i}^{\mathrm{B} 2 \mathrm{G}}(t)+\aleph_{i}^{\mathrm{P} 2 \mathrm{G}}(t)>0$ and $\aleph_{i}^{\mathrm{G} 2 \mathrm{~B}}(t)=\aleph_{i}^{\mathrm{G} 2 \mathrm{~L}}(t)=0$, or iii) flexible (can either be buyer or seller), i.e., $\underline{\aleph}_{i}(t)<0, \bar{\aleph}_{i}(t)>0$.

\section{B. Aggregator}

The aggregator holds no physical connection with the grid and is only responsible for trading prosumers' flexibility in the market while making profitable contracts [30]. The aggregator makes decisions in response to prosumers' surplus and shortage based on the following optimization model:

$$
\underset{\left\{\widetilde{\aleph}_{i}(t), \widetilde{p}_{i}(t)\right\}_{i=1}^{m}}{\operatorname{maximize}} \Delta t \cdot \sum_{i=1}^{m} \begin{cases}\widetilde{\aleph}_{i}(t) \cdot\left(p_{\mathcal{G}}^{l}(t)-\widetilde{p}_{i}(t)\right) & \widetilde{\aleph}_{i}(t)>0, \\ \widetilde{\aleph}_{i}(t) \cdot\left(\widetilde{p}_{i}(t)-p_{\mathcal{G}}^{u}(t)\right) & \widetilde{\aleph}_{i}(t)<0,\end{cases}
$$

$\underset{\left\{\widetilde{\aleph}_{i}(t)\right\}_{i=1}^{m}}{\operatorname{minimize}}-\sum_{i=1}^{m} \widetilde{\aleph}_{i}(t)$

subject to

$$
\left\{\begin{array}{l}
{\left[\begin{array}{l}
0<\widetilde{\aleph}_{i}(t) \leq \max _{\forall \rho_{i} \in \mathcal{P}} \bar{\aleph}_{i}(t) \\
p^{l}(t) \leq \widetilde{p}_{i}(t) \leq p_{\mathcal{G}}^{l}(t)
\end{array} \quad \aleph_{i}(t)>0, \forall \rho_{i} \in \mathcal{P},\right.} \\
\min _{\forall \rho_{i} \in \mathcal{P}} \aleph_{i}(t) \leq \widetilde{\aleph}_{i}(t)<0 \\
p_{\mathcal{G}}^{u}(t) \leq \widetilde{p}_{i}(t) \leq p^{u}(t)
\end{array} \quad \aleph_{i}(t)<0, \forall \rho_{i} \in \mathcal{P},\right.
$$$$
\sum_{i=1}^{m} \widetilde{\aleph}_{i}(t)+\widetilde{\aleph}_{\mathcal{A}}(t)=0
$$

where the aggregator, similar to prosumers, confronts with a multi-objective optimization problem making trade-off over two objectives. Eq. (18) attempts to maximize the aggregator's profit by selling more power to buyer prosumers with high price and buying less power from seller prosumers who offer prices higher than grid. This leads to buying more power from the grid. Eq. (19), however, aims at minimizing the grid burden. $\widetilde{\aleph}_{i}(t) \in \mathbb{R}(\mathrm{kW})$ is the amount of power the aggregator is interested in trading with prosumer $\rho_{i}$ with a price offer $\widetilde{p}_{i}(t) \in \mathbb{R}_{>0}(\$ / \mathrm{kWh})$. Eq. (20) prevents the aggregator from requesting buyer prosumers to sell and vice versa. $\widetilde{\aleph}_{\mathcal{A}}(t) \in \mathbb{R}(\mathrm{kW})$ is the amount of electric power that the aggregator exchanges with the grid (matching supply with demand). $p_{\mathcal{G}}^{l}(t), p_{\mathcal{G}}^{u}(t) \in \mathbb{R}_{>0}(\$ / \mathrm{kWh})$ are the grid's prices for buying/selling energy from/to the aggregator, respectively.

\section{NSGA-III: An EvolutionARy Multi-ObJective OPTIMIZATION ALGORITHM}

Typically, there exists no unique optimal solution to multiobjective optimization problems of prosumers and the aggregator including multiple conflicting criteria. Hence, the concept of an optimal solution is replaced by the set of non-dominated solutions in the objectives space. A non-dominated solution is a solution from which moving to any other solution requires a trade off with at least one objective value. 
This paper employs the evolutionary NSGA-III [23], [31] to produce $K \in \mathbb{N}$ feasible and well-spread solutions to the optimization problem of each independent prosumer as well as the aggregator, using a systematic decompositionbased reference-point-based non-dominated sorting approach. These solutions lie on the first Pareto-front (after running a pre-defined number of generations). The NSGA-III places reference points on a rectangle with a number of divisions along each objective axis in the objective space [23]. This approach is maintained by making one individual solution associated with one reference point. Therefore, the generated solutions are likely to be widely distributed on the Paretofront, since the reference points are widely distributed on the objective space. The computational complexity of one generation of the NSGA-III is $O\left(2 \cdot K^{2}\right)$, whereas for the NSGA-II, it is $O\left(2 \cdot K^{3}\right)$ [32].

The main part in the NSGA-III is to generate an initial set of feasible solutions. For each prosumer $\rho_{i} \in \mathcal{P}$, let

$$
\begin{aligned}
& \mathcal{B} \mathcal{P}_{i}^{k}(t) \triangleq\left(\aleph_{i}^{k}(t), p_{i}^{k}(t)\right), \\
& \mathcal{S I}_{i}^{k}(t) \triangleq \begin{cases}\frac{\aleph_{i}^{k}(t)}{\overline{\aleph_{i}(t)}}+\frac{p_{i}^{k}(t)}{p^{u}(t)} & \aleph_{i}^{k}(t)>0, \\
\frac{\aleph_{i}(t)}{\aleph_{i}(t)}+\frac{p^{l}(t)}{p_{i}^{k}(t)} & \aleph_{i}^{k}(t)<0,\end{cases}
\end{aligned}
$$

where behavior pair $\mathcal{B P}_{i}^{k}(t), 1 \leq k \leq K$ is a feasible solution to the prosumer's optimization problem. Fig. 3 shows how such behavior pair, according to (1)-(10) and (13)-(17), is randomly generated. Depending on the prosumer's status (i.e., buyer, seller, or silent), satisfaction index $\mathcal{S I}_{i}^{k}(t) \in(0,2]$ is a measure, which shows to which extent $\mathcal{B P}_{i}^{k}(t)$ uses the available flexibility and provides a more beneficial price offer [8], [12]. This index is maximized when: i) a buyer prosumer purchases the lowest possible amount of power $\left(\aleph_{i}(t)\right)$ at the lowest possible price $\left(p^{l}(t)\right)$, or ii) a seller prosumer sells the maximum possible amount of electricity $\left(\bar{\aleph}_{i}(t)\right)$ at the highest possible price $\left(p^{u}(t)\right)$.

Similar to prosumers, the aggregator also benefits from the NSGA-III to generate $K$ feasible non-dominated solutions to its optimization problem. Let

$$
\begin{aligned}
& \widetilde{\mathcal{B M}}_{\mathcal{A}}(t) \triangleq\left[\begin{array}{c}
\widetilde{\mathcal{B P}}_{1}^{\widetilde{k}}(t) \\
\vdots \\
\widetilde{\mathcal{B P}}_{m}^{\widetilde{k}}(t)
\end{array}\right] \text {, } \\
& \widetilde{\mathcal{B P}}_{i}^{\widetilde{k}}(t) \triangleq\left(\widetilde{\aleph}_{i}^{\widetilde{k}}(t), \widetilde{p}_{i}^{\widetilde{k}}(t)\right) \text {, } \\
& \mathcal{S I}_{\mathcal{A}}^{\widetilde{k}}(t) \triangleq \frac{1}{m} \cdot \sum_{i=1}^{m} \begin{cases}\frac{\widetilde{\aleph}_{i}^{\tilde{k}}(t)}{\max _{\forall \rho_{i} \in \mathcal{P}} \bar{\aleph}_{i}(t)}+\frac{p^{l}(t)}{\widetilde{p}_{i}^{\tilde{k}}(t)} & \widetilde{\aleph}_{i}^{\widetilde{k}}(t)>0, \\
\frac{\widetilde{\aleph}_{i}^{\underline{k}}(t)}{\min _{\forall \rho_{i} \in \mathcal{P}} \aleph_{i}(t)}+\frac{\widetilde{p}_{i}^{\widetilde{k}}(t)}{p^{u}(t)} & \widetilde{\aleph_{i}^{k}}(t)<0,\end{cases}
\end{aligned}
$$

where behavior matrix $\widetilde{\mathcal{B M}}_{\mathcal{A}}^{\widetilde{k}}(t), 1 \leq \widetilde{k} \leq K$ includes $m$ behavior pairs $\widetilde{\mathcal{B P}}_{i}^{\widetilde{k}}(t), \forall \rho_{i} \in \mathcal{P}$. Fig. 4 shows how a feasible behavior matrix, according to (20), is randomly generated. Each of which is the aggregator's action in response to the behavior pair of a prosumer. Satisfaction in-

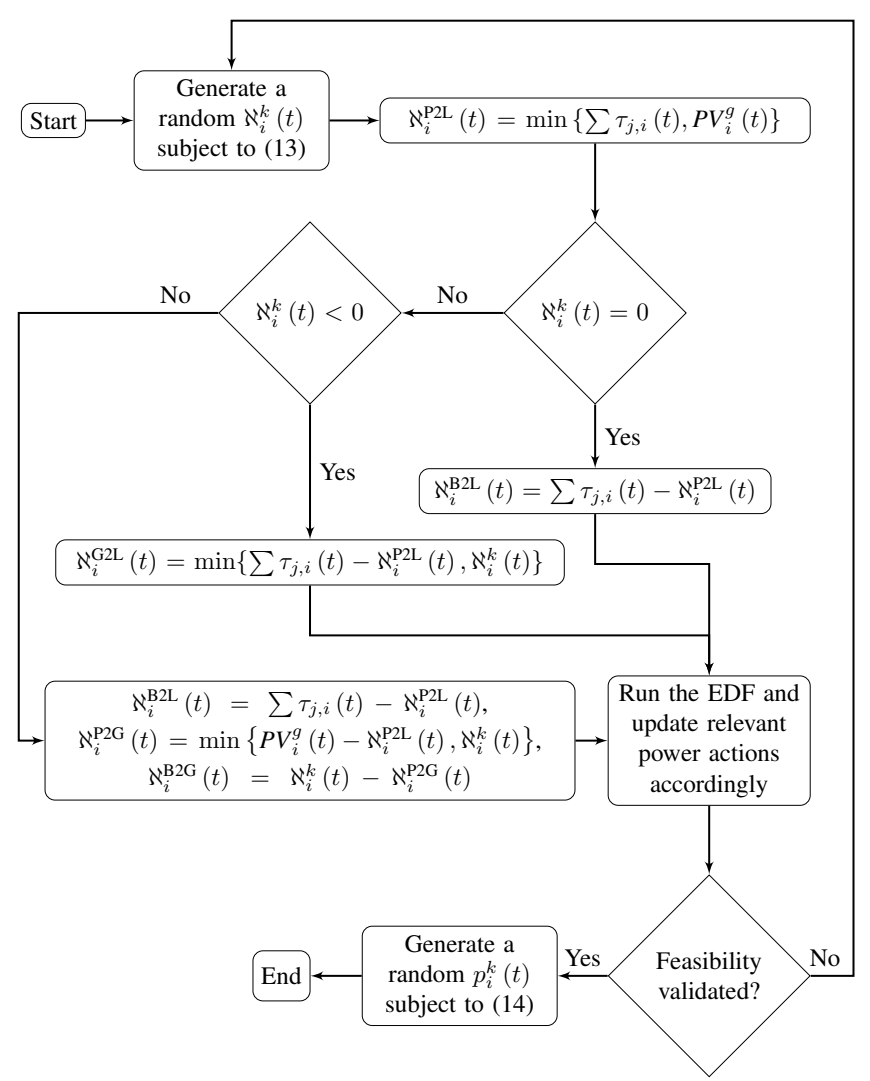

Fig. 3. Flowchart of generating a feasible behavior pair $\mathcal{B P}_{i}^{k}(t)$, where $\sum \tau_{j, i}(t)$ is the summation of load demands of appliances with insufficient flexibility. Earliest Deadline First (EDF) mechanism [9] is applied on the remaining appliances and relevant power actions are, then, updated. Feasibility is related to constraints formulated in each prosumer's MO-MINLP.

$\operatorname{dex} \mathcal{S I}_{\mathcal{A}}^{\widetilde{k}}(t) \in(0,2]$ determines how much the aggregator is satisfied with $\widetilde{\mathcal{B M}}_{\mathcal{A}}(t)$.

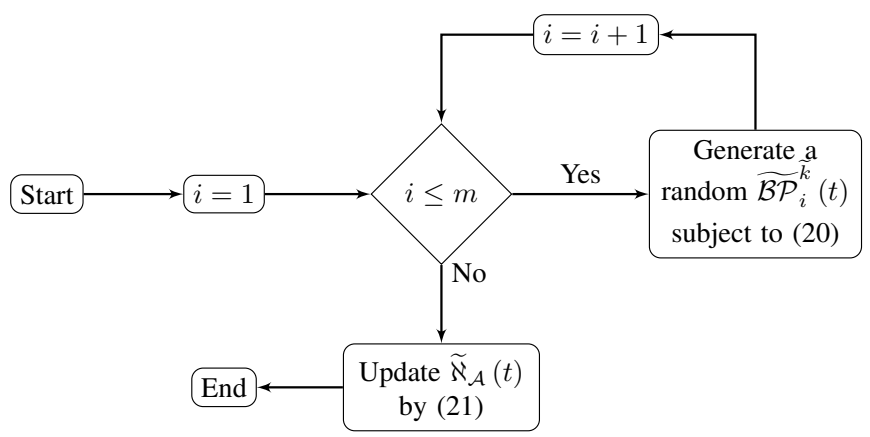

Fig. 4. Flowchart of generating a feasible behavior matrix $\widetilde{\mathcal{B M}}_{\mathcal{A}}^{\widetilde{k}}(t)$.

\section{Negotiation APPROACH}

Prosumers' rational behaviors are more conspicuous when the uncertainty about the aggregator's decision space increases. This paper employs a novel negotiation approach, proposed in [24]. This approach facilitates the concurrent negotiation on power and price with offer packages between negotiators provably coming to an agreement, given that negotiators are reactive and no private information is shared. To the best of our 
knowledge, this paper is among the first attempts, that tackles the peer-to-peer automated energy trading problem with designing (close to real-life) MO-MINLP models integrated with a fully adaptive real-time negotiation approach.

\section{A. Formulation of Offer Packages and Utility Functions}

This paper, to alleviate the challenges of parallel bilateral negotiations between $m$ prosumers and the aggregator, utilizes an intermediate VPP to negotiate on behalf of prosumers. The negotiators (i.e., the VPP and the aggregator) conduct the negotiation procedure between each two time intervals $t$ and $t+\Delta t$ for maximum $\mathcal{T} \geq 2 \in \mathbb{N}$ iterations, which is set arbitrarily. The following defines how an offer package for each negotiator is formulated and evaluated through its relevant utility function defined.

1) VPP: Let

$$
\sigma_{\mathcal{V}}(\iota)=\left[\begin{array}{c}
\mathcal{B P}_{1}^{k}(t) \\
\vdots \\
\mathcal{B} \mathcal{P}_{m}^{k^{\prime}}(t)
\end{array}\right],
$$

where $\sigma_{\mathcal{V}}(\iota)$ is an offer package that the VPP produces and sends to the aggregator at negotiation iteration $1 \leq \iota \leq \mathcal{T}$. Superscripts $k$ in $\mathcal{B P}_{i}^{k}(t), \forall \rho_{i} \in \mathcal{P}$ and $k^{\prime}$ in $\mathcal{B P}_{i^{\prime}}^{\overline{k^{\prime}}}(t), \forall \rho_{i^{\prime}} \in$ $\mathcal{P}$, where $1 \leq k, k^{\prime} \leq K$, are not necessarily equivalent. Let

$$
\begin{aligned}
& \psi_{\mathcal{V}}\left(\mathcal{S I}_{\mathcal{V}}(\iota)\right)=1-\frac{\sum_{i=1}^{m}\left(\frac{1}{2} \cdot \mathcal{S I}_{i}^{k}(t)\right)^{2}}{m}, \\
& \mathcal{S I}_{\mathcal{V}}(\iota) \triangleq \bigcup_{i=1}^{m} \mathcal{S I}_{i}^{k}(t), 1 \leq k \leq K,
\end{aligned}
$$

where $\psi_{\mathcal{V}} \in[0,1)$ is the VPP's private, continuous, and strictly concave utility function [24], [33]. Due to privacy concerns, negotiators have no knowledge about each other's utility function. Basically, such functions return the utility value of a single offer package, e.g., $\sigma_{\mathcal{V}}(\iota), \forall \iota \leq \mathcal{T}$, by receiving its corresponding satisfaction index, i.e., $\mathcal{S I}_{\mathcal{V}}(\iota)$. This satisfaction index is the union of satisfaction indexes $\mathcal{S I}_{i}^{k}(t), \forall \rho_{i} \in \mathcal{P}$ of $\mathcal{B} \mathcal{P}_{i}^{k}(t), \forall \rho_{i} \in \mathcal{P}$ stored in $\sigma_{\mathcal{V}}(\iota)$. Let

$$
\begin{aligned}
& \sigma_{\mathcal{V}}^{\text {res }}(t)=\left[\begin{array}{c}
\mathcal{B P}_{1}^{\text {res }}(t) \\
\vdots \\
\mathcal{B P}_{m}^{\text {res }}(t)
\end{array}\right], \\
& \mathcal{B P}_{i}^{\text {res }}(t)=\left(\aleph_{i}^{\text {res }}(t), p_{i}^{\text {res }}(t)\right), \\
& \aleph_{i}^{\text {res }}(t)=\left\{\begin{array}{cc}
\aleph_{i}(t) & \sum_{\substack{\operatorname{flx}_{j, i}(t)=0, \forall a_{j, i} \in \mathcal{A} \mathcal{P}_{i}}} \tau_{j, i}(t) \leq P V_{i}^{g}(t), \\
\aleph_{i}(t) & \text { otherwise, }
\end{array}\right. \\
& p_{i}^{r e s}(t)= \begin{cases}p^{l}(t) & \aleph_{i}^{r e s}(t)>0, \\
p^{u}(t) & \aleph_{i}^{r e s}(t)<0,\end{cases}
\end{aligned}
$$

where $\sigma_{\mathcal{V}}^{\text {res }}(t)$ is the reservation offer package of the VPP including prosumers' reservation behavior pairs $\mathcal{B P}_{i}^{\text {res }}(t), \forall \rho_{i} \in$ $\mathcal{P}$. $\aleph_{i}^{\text {res }}(t) \in \mathbb{R}(\mathrm{kW})$ and $p_{i}^{\text {res }}(t) \in \mathbb{R}_{>0}(\$ / \mathrm{kWh})$ are the reservation power and price offers of prosumer $\rho_{i}$ at time interval $t$. Prosumers in the worst case have to: i) satisfy appliances with no flexibility remained $\left(\operatorname{flex}_{j, i}(t)=0, \forall a_{j, i} \in\right.$
$\mathcal{A} \mathcal{P}_{i}, \forall \rho_{i} \in \mathcal{P}$ ), and ii) utilize the electric power generated by the PV completely. Then, the reservation price offer, depending on the status of the reservation power, will either be the lowest or highest possible offerable electricity price. $\mathcal{S I}_{\mathcal{V}}^{\text {res }}(t) \in(0,2]$, as the satisfaction index of $\sigma_{\mathcal{V}}^{\text {res }}(t)$, is the union of $\mathcal{S I}_{i}^{\text {res }}(t) \in(0,2], \forall \rho_{i} \in \mathcal{P}$ (calculated by (23)) associated with $\mathcal{B P}_{i}^{\text {res }}(t), \forall \rho_{i} \in \mathcal{P}$. VPP will not accept any offer package with the utility value less than $\psi_{\mathcal{V}}\left(\mathcal{S I}_{\mathcal{V}}^{\text {res }}(t)\right)$.

2) Aggregator: Let

$$
\sigma_{\mathcal{A}}(\iota)=\widetilde{\mathcal{B M}}_{\mathcal{A}}^{\widetilde{k}}(t),
$$

where $\sigma_{\mathcal{A}}(\iota)$ (equivalent to $\widetilde{k}$-th behavior matrix, see (24)) is an offer package that the aggregator produces and sends to the VPP at negotiation iteration $\iota$. Let

$$
\psi_{\mathcal{A}}\left(\mathcal{S I}_{\mathcal{A}}^{\widetilde{k}}(t)\right)=1-\left(\frac{1}{2} \cdot \mathcal{S I}_{\mathcal{A}}^{\widetilde{k}}(t)\right)^{2},
$$

where $\psi_{\mathcal{A}} \in[0,1)$ is the aggregator's private, continuous, and strictly concave utility function [24], [33]. Let

$$
\begin{aligned}
& \sigma_{\mathcal{A}}^{\text {res }}(t)=\left[\begin{array}{c}
\widetilde{\mathcal{B P}}_{1}^{\text {res }}(t) \\
\vdots \\
\widetilde{\mathcal{B P}}_{m}^{\text {res }}(t)
\end{array}\right], \\
& \widetilde{\mathcal{B P}}_{i}^{\text {res }}(t)=\left(\min _{\forall \rho_{i} \in \mathcal{P}} \underline{\aleph}_{i}(t), p^{l}(t)\right),
\end{aligned}
$$

where $\sigma_{\mathcal{A}}^{r e s}(t)$ is the reservation offer package of the aggregator denoting $m \cdot \min _{\forall \rho_{i} \in \mathcal{P}} \underline{\aleph}_{i}(t)$ amount of electric power must be exchanged (in the worst case) with the grid for $p^{l}(t)$. It is coupled with a satisfaction index $\mathcal{S I}_{\mathcal{A}}^{\text {res }}(t) \in(0,2]$ (calculated by (26)). Similarly, the aggregator will not accept any offer package with the utility value less than $\psi_{\mathcal{A}}\left(\mathcal{S I}_{\mathcal{A}}^{\text {res }}(t)\right)$. The negotiation approach, to guarantee the convergence to an acceptable agreement in a non-cooperative environment within a reasonable time frame, requires negotiators to define private reservation offer packages, formulated as the worst but still feasible offer packages [24]. The VPP, by (30), ensures all prosumers that their non-flexible appliances operate uninterruptedly until completion. The aggregator, on the other hand, is guaranteed by (36) to receive the lowest possible profit, despite having the lowest possible amount of exchange.

\section{B. Negotiation Protocol and Strategy}

We employ an alternating-offer production protocol [34], where the VPP produces an offer and the aggregator either accepts it or makes a new one. The negotiation begins with offer packages produced with the highest possible utility values and continues with offer packages with lower utility values until reaching the reservation offer packages. It terminates when both negotiators accept the offer on the table or it reaches iteration $\mathcal{T}$. Negotiators, at each negotiation iteration, produce (and only accept) an offer package that provides a utility value equivalent to or higher than their desired utility value at that iteration (or their reservation utility value). To produce new offer packages over negotiation iterations, they follow reactive utility value concession strategy [24]. It assumes 
negotiators are reactive to the concession strategies of the other agents. Their concession rate depends on: i) whether the current offer of the opponent negotiator provides higher utility value than the negotiator's reservation utility value, and ii) the negotiator's perception of how much the other party has conceded. It is also assumed that each negotiator's utility value obtained by an agreement is higher than the one with no agreement. Therefore, they prefer to concede over risking negotiation breakdown. Let

$$
\begin{aligned}
& \varsigma_{\mathcal{V}}(\iota)=\psi_{\mathcal{V}}\left(\mathcal{S I}_{\mathcal{V}}(1)\right)-\sigma_{\mathcal{V}}^{r e s}(t) \cdot\left(\frac{\iota}{\mathcal{T}}\right)^{\frac{1}{\epsilon}}, \\
& \varsigma_{\mathcal{A}}(\iota)=\psi_{\mathcal{A}}\left(\mathcal{S I}_{\mathcal{A}}(1)\right)-\sigma_{\mathcal{A}}^{r e s}(t) \cdot\left(\frac{\iota}{\mathcal{T}}\right)^{\frac{1}{\epsilon}},
\end{aligned}
$$

where $\varsigma_{\mathcal{V}}(\iota), \varsigma_{\mathcal{A}}(\iota) \in[0,1)$ are monotonically decreasing time-dependent concession values of the VPP and aggregator, respectively. Their values only depend on each negotiator's reservation utility value and the number of negotiation iterations passed with the decay rate $\epsilon \in \mathbb{R}_{>0}$ [35]. One reason for a negotiator to stop decreasing its desired utility value over time is to gain higher utility. This happens when the other negotiator, without realizing that the negotiator has stopped conceding, accepts time-dependent concession values at all negotiation iterations. This behavior is called the "deliberate stopping of concession." As a result, let

$$
\begin{aligned}
& \omega_{\mathcal{V}}(\iota)=\left(\psi_{\mathcal{V}}\left(\mathcal{S I}_{\mathcal{V}}^{\text {temp }}\right)-\psi_{\mathcal{V}}\left(\mathcal{S I}_{\mathcal{V}}^{\text {temp }}\right)^{\prime}\right) \\
& \omega_{\mathcal{A}}(\iota)=\left(\psi_{\mathcal{A}}\left(\mathcal{S I}_{\mathcal{A}}^{t e m p}\right)-\psi_{\mathcal{A}}\left(\mathcal{S I}_{\mathcal{A}}^{\text {temp }}\right)^{\prime}\right)
\end{aligned}
$$

where $\omega_{\mathcal{V}}(\iota), \omega_{\mathcal{A}}(\iota) \in[0,1)$ are reactive concession values of the VPP and aggregator, respectively. Note that $y^{+}=\max \{0, y\}$. The VPP, using (23), calculates $\mathcal{S I}_{\mathcal{V}}^{\text {temp }}$ and $\mathcal{S I}_{\mathcal{V}}^{\text {temp }}{ }^{\prime}$ for $\sigma_{\mathcal{A}}(\iota)$ and $\sigma_{\mathcal{A}}(\iota-1)$, respectively. The aggregator, by using (26), follows a similar procedure. Then, let

$$
\begin{aligned}
& \Pi_{\mathcal{V}}(\iota)=\min \left\{\varsigma_{\mathcal{V}}(\iota), \Pi_{\mathcal{V}}(\iota-1)-\omega_{\mathcal{V}}(\iota)\right\} \\
& \Pi_{\mathcal{A}}(\iota)=\min \left\{\varsigma_{\mathcal{A}}(\iota), \Pi_{\mathcal{A}}(\iota-1)-\omega_{\mathcal{A}}(\iota)\right\},
\end{aligned}
$$

where $\Pi_{\mathcal{V}}(\iota), \Pi_{\mathcal{A}}(\iota) \in[0,1)$ are desired utility values of the VPP and the aggregator at iteration $\iota$, respectively. To produce a new offer package based on $\Pi_{\mathcal{V}}(\iota), \Pi_{\mathcal{A}}(\iota), \forall \iota \leq \mathcal{T}$, let us assume $Z_{\mathcal{V}}(t)$ (including maximum $K^{m}$ offer packages) and $Z_{\mathcal{A}}(t)$ (including maximum $K$ possible feasible offer packages) are the convex feasible offer package sets of the VPP and the aggregator, respectively. These offer packages provide negotiators with utility value equivalent to or no less than their reservation offer package's utility value. For an agreement to exist, let $\mathscr{Z}(t)=Z_{\mathcal{V}}(t) \cap Z_{\mathcal{A}}(t) \neq \varnothing, \forall t$ remain unchanged during the negotiation, where $\mathscr{Z}(t)$ is the zone of agreement denoting the common intersection of the feasible offer package sets. If an offer package is within $\mathscr{Z}(t)$, a negotiator may not accept it if it yields a utility value lower than the negotiator's current desired utility value [24]. To make an acceptable agreement, negotiators keep conceding to their reservation utility values subject to the nonempty zone of agreement at each time interval. Geometrically speaking, the main goal is to find a point in the zone of agreement, under the restriction that this zone is unknown to negotiators and none of them has any explicit knowledge about each other's utility functions [24].

Let $\iota$ be the negotiation iteration when it is the VPP's turn to produce a new offer package. Let $\mathcal{B P}_{i}^{k}(t) \in \sigma_{\mathcal{V}}(\iota-1)$, where $\exists \rho_{i} \in \mathcal{P}$. The VPP (temporarily) updates $\sigma_{\mathcal{V}}(\iota-1)$ with behavior pairs $\mathcal{B P}_{i}^{k^{\prime}}(t), \forall k+1 \leq k^{\prime} \leq K$ and expands $\bar{Z}_{\mathcal{V}}(\iota)$ with the updated offer packages individually only if each returns a utility value equivalent to $\Pi_{\mathcal{V}}(\iota)$. $\bar{Z}_{\mathcal{V}}(\iota) \subseteq Z_{\mathcal{V}}(t), \forall \iota \leq \mathcal{T}$ is the continuously expanding feasible offer package subset of the VPP. The aggregator at iteration $\iota+1$ updates $\bar{Z}_{\mathcal{A}}(\iota+1)$ with new offer packages $\widetilde{\mathcal{B M}}_{\mathcal{A}}^{\widetilde{k}+1}(t), \forall \widetilde{k}+1 \leq K$, where each provides the aggregator with a utility value equivalent to $\Pi_{\mathcal{A}}(\iota+1)$. $\bar{Z}_{\mathcal{A}}(\iota) \subseteq Z_{\mathcal{A}}(t), \forall \iota \leq \mathcal{T}$ is the continuously expanding feasible offer package subset of the aggregator. Let

$$
\begin{aligned}
& \sigma_{\mathcal{V}}(\iota)=P_{\bar{Z}_{\mathcal{V}(\iota)}}[\chi(\iota)]=\underset{q \in \bar{Z}_{\mathcal{V}}(\iota)}{\arg \min }\|q-\chi(\iota)\|, \\
& \sigma_{\mathcal{A}}(\iota)=P_{\bar{Z}_{\mathcal{A}}(\iota)}[\chi(\iota)]=\underset{q \in \bar{Z}_{\mathcal{A}}(\iota)}{\arg \min }\|q-\chi(\iota)\|, \\
& \chi(\iota)=\varphi_{\mathcal{V}}(\iota) \cdot \sigma_{\mathcal{V}}(\iota-1)+\varphi_{\mathcal{A}}(\iota) \cdot \sigma_{\mathcal{A}}(\iota-1), \\
& \varphi_{\mathcal{V}}(\iota)+\varphi_{\mathcal{A}}(\iota)=1,
\end{aligned}
$$

where $P$ is the operator of projecting the weighted offer package $\chi(\iota)$, created based on the latest offers made by all agents, on current continuously expanding feasible offer package subsets $\bar{Z}_{\mathcal{V}}(\iota)$ and $\bar{Z}_{\mathcal{A}}(\iota)$ [36]. arg min $\|\cdot\|$ is the Frobenius norm with argument of minimum. This method generates an offer that is acceptable to the relevant negotiator and is closest (in terms of Euclidean distance) to the weighted offer package $\chi(\iota)$. Notations $\varphi_{\mathcal{V}}(\iota), \varphi_{\mathcal{A}}(\iota) \in(0,1)$ are the weights that each negotiator puts on the other's offer package.

\section{Algorithms of the Overall Computational Steps and the Negotiation Approach}

Algorithms 1 provides the pseudo-code for the overall computational steps in the framework between each two time intervals $t$ and $t+\Delta t$. Prosumers, e.g., via their home energy management gateways, independently forward their behavior and the reservation pairs to the VPP. At the same time, the aggregator produces its own behavior and reservation matrices. Both the VPP and the aggregator are most likely hosted e.g., in the cloud. Then, as Algorithm 2 describes, the negotiation approach starts with the second iteration and continues for maximum $\mathcal{T}$ iterations. Finally, the VPP returns the indexes of agreed behavior pairs to the prosumers. Algorithm 2 basically follows the negotiation protocol and strategy developed in Section IV-B. We define a binary flag IsConverge to determine when the negotiation approach, apart from reaching the maximum number of iterations $\mathcal{T}$, terminates. Depending on the negotiator's turn determined by $S \in \mathbb{B}$, the corresponding negotiator attempts to produce a new offer package whereas the other negotiator remains with its previous offer package. Following the same principle, Found $\in \mathbb{B}$ assures whether a temporarily produced offer package is equal to the desired utility value. Fig. 5 conceptualizes the offer package space showing how the VPP and the aggregator negotiate with each 


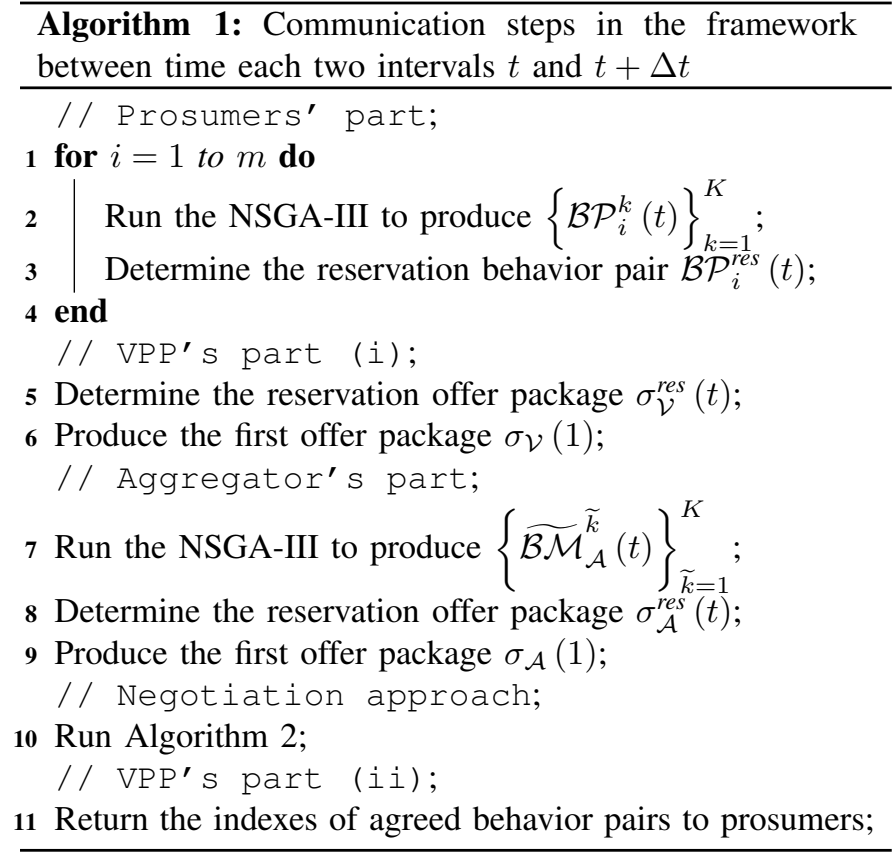

other over, for example, $\mathcal{T}=9$ iterations [24]. Offer packages existing on each concession curve have equal utility values (see lines 16 and 35 in Algorithm 2). The negotiation terminates when the maximum of Euclidean distances between the current iteration's offer packages and the weighted offer package are less than a constant convergence tolerance $\delta \in \mathbb{R}_{>0}$ (see line 48 in Algorithm 2). The computational complexity of the negotiation approach is $O(\mathcal{T} \cdot m \cdot K)$ [24].

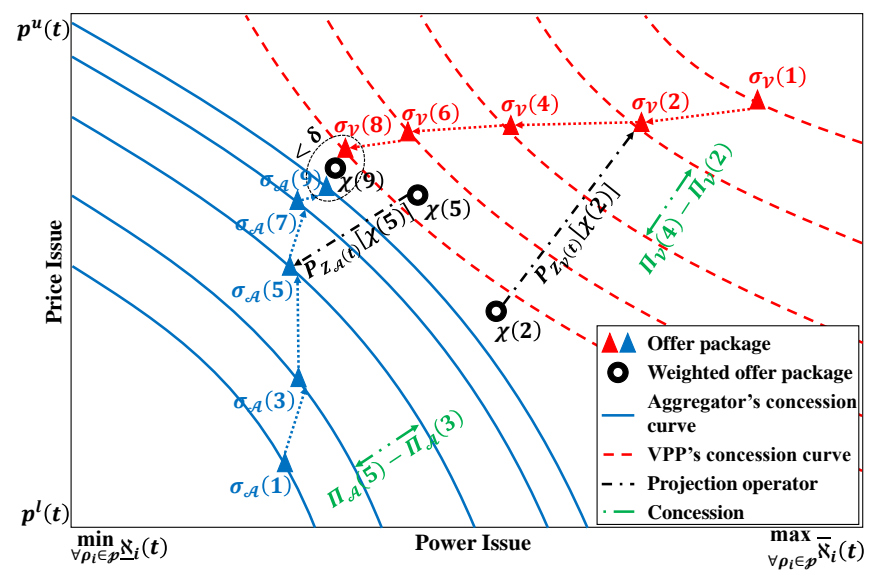

Fig. 5. Conceptual example of the offer package space during the negotiation.

\section{Solution Concept for the Negotiation Approach}

The authors in [24] analytically demonstrate that the solution concept for the proposed negotiation approach is in the spirit of Herbert Simon [37]. The negotiation approach, without computing all solution points (i.e., offer packages), yields a performance sufficiently close to the Nash bargaining solution [38]. The scale of the utility value of each negotiator is of no critical importance, as long as the reservation utility value and the scale of concession are consistent with the utility

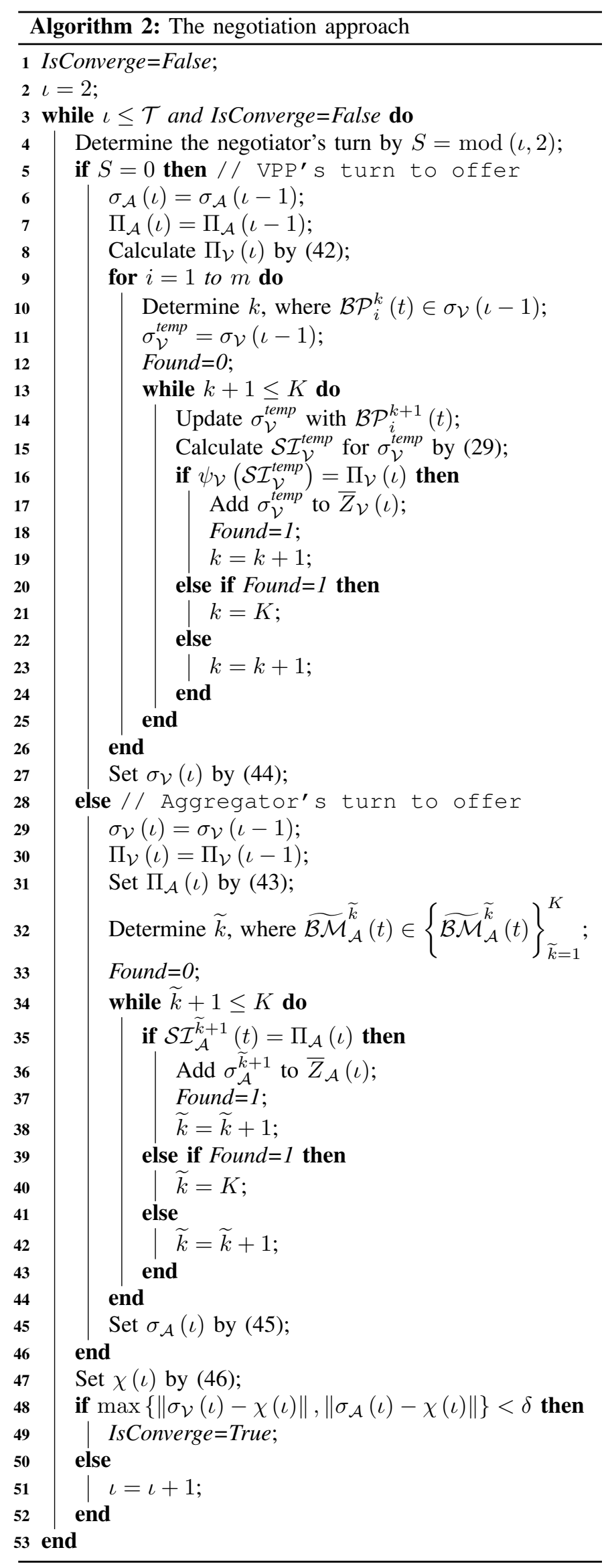


value. The negotiation converges in maximum $\mathcal{T}$ iterations, if they concede to reservation utility values in the worst case and the zone of agreement is nonempty. The convergence holds for all strictly concave utility functions irrespective of the specific concession strategy the negotiators adopt.

\section{NUMERICAl SimUlation AND DiscUSSION}

This section evaluates the performance of the proposed framework, which has been implemented in Matlab ${ }^{\circledR}$ R2017a running with 16 Intel $2.3 \mathrm{GHz}$ Xeon ${ }^{\circledR}$ E5-2686 CPUs and 64 GB memory. All simulation results have been averaged over 100 independent runs.

\section{A. Performance Assessment Metrics}

To assess the performance of the framework, we define the following metrics: Peak Demand Reduction (PDR) to determine how much the peak demand is shaved; Peak-toAverage Ratio (PAR) to measure how much higher the peak demand is than average demands in a single simulation; Average Appliance Operation Delay (AOD) to measure the delay in delivering appliances in the completed status; Average Flexibility Usage Rate (FUR) to determine how much of prosumers' flexibility is traded in the market; Average Prosumer Cost-Benefit (PCB) to study how much money the prosumers averagely earn/spend with and without exchanging power with the grid; Average Self Load-Satisfaction Rate (SLR) to measure the local self satisfaction of prosumers; and Average Self Sufficiency Rate (SSR) to evaluate PVs' capability in maximizing the comfort level of prosumers without purchasing any amount of power from the grid.

\section{B. Simulation Setup and Scenario}

Table I lists the inputs and Table II describes consumption scenarios, assumed constant in simulations, unless otherwise stated. For the PV generation profile, the real data is captured from the UCLA Ackerman Union and scaled down from the capacity of $35 \mathrm{~kW}$ to $7 \mathrm{~kW}$ [39]. Operation and flexibility times are randomly generated by the normal distribution $\mathcal{N}\left(\mu, \sigma^{2}\right)$ with mean $\mu \in \mathbb{R}$ and variance $\sigma^{2}>0$. Load profiles of appliances are captured from [40], [41] with time resolution of $\Delta t=1$ hour. Nissan Altra is chosen as the electric vehicle with an empty battery at arrival and fully charged battery at departure. The deadline flexibility concept from the perspective of an air conditioner is the comfortable temperature range, where $25^{\circ} \mathrm{C}$ and $\pm 3^{\circ} \mathrm{C}$ are prosumers' desired temperature set point and flexibility, respectively. Note that a full simulation starts at midnight and terminates when the last appliance finishes operating. Real-time hourly electricity prices are captured from Nord Pool Spot [42], where $\left\{p^{l}(t), p^{u}(t)\right\},\left\{p_{\mathcal{G}}^{l}(t), p_{\mathcal{G}}^{u}(t)\right\}, \forall t$ are adjusted by fluctuation rates of $\pm 50 \%$ and $\pm 20 \%$, respectively.

\section{Analysis and Discussion}

Fig. 6 shows the offer package and utility value concession spaces of randomly picked time intervals in different circumstances for 100 prosumers. Points in the offer package spaces,
TABLE I

CONSTANT INPUTS IN ALL SIMULATIONS, UNLESS OTHERWISE STATED.

\begin{tabular}{llllll}
\hline Parameter & Value & Parameter & Value & Parameter & Value \\
\hline$\Delta t$ & 1 hour & $P V_{i}^{\text {cap } \dagger *}$ & $7 \mathrm{~kW}$ & $B_{i}^{c a p *}$ & $13.2 \mathrm{kWh}$ \\
$B_{i}^{\bar{c} *}$ & $5 \mathrm{~kW}$ & $B_{i}^{\bar{d} *}$ & $5 \mathrm{~kW}$ & $\mathcal{T}$ & 100 \\
$\epsilon$ & 0.8 & $\delta$ & 0.01 & $\varphi_{\mathcal{V}}(\iota)^{\ddagger}, \varphi_{\mathcal{A}}(\iota)^{\ddagger}$ & 0.5 \\
\hline${ }^{*} \forall \rho_{i} \in \mathcal{P} .^{\dagger}$ Data for a sunny day is used. ${ }^{\stackrel{*}{ } \forall \iota \leq \mathcal{T} .}$
\end{tabular}

TABLE II

TIMETABLE OF GENERATING LOAD DEMAND SCENARIOS OF APPLIANCES.

\begin{tabular}{llll}
\hline$a_{j, i} \in \mathcal{A} \mathcal{P}_{i}, \forall \rho_{i} \in \mathcal{P}$ & $\alpha_{j, i}$ & $\beta_{j, i}$ & $\theta_{j, i}$ \\
\hline Refrigerator (RG) & $00: 00$ & $24: 00$ & $24: 00$ \\
Washing Machine (WM) & $\mathcal{N}(10,3)$ & $\alpha_{j, i}+02: 00$ & $\mathcal{N}(16,4)$ \\
Laundry Dryer (LD) & $\mathcal{N}(15,1)$ & $\alpha_{j, i}+01: 30$ & $\mathcal{N}(21,5)$ \\
Dishwasher (DW) & $\mathcal{N}(17,2)$ & $\alpha_{j, i}+01: 40$ & $\mathcal{N}(23,2)$ \\
Electric Vehicle (EV) & $\mathcal{N}(19,10)$ & $\alpha_{j, i}+05: 00$ & $\mathcal{N}(7.5,1)^{*}$ \\
Air Conditioner (AC) & $\mathcal{N}(9,1)$ & $\mathcal{N}(21,2)$ & $25^{\circ} \mathrm{C} \pm 3^{\circ} \mathrm{C}$ \\
\hline
\end{tabular}

* The next day.

for the sake of simplicity, represent the summation of power and the average of price values of columns in the behavior matrices. Utility values are unitless, (see (28) and (35)). In Fig. 6(a), no PVs and BESSs are considered. The VPP, for example at negotiation iteration $\iota=15$, is interested in buying $1630 \mathrm{~kW}$ of electric power for $0.0145 \$ / \mathrm{kWh}$. The aggregator, then, rejects this offer and makes a new one intending to sell $2180 \mathrm{~kW}$ of electric power for $0.022 \$ / \mathrm{kWh}$. They continue negotiating until iteration $\iota=31$, at which they come to an agreement on exchanging $2000 \mathrm{~kW}$ of electric power for $0.016 \$ / \mathrm{kWh}$. Fig. 6(b) shows the negotiation process, where all prosumers own PV and BESS. They reach an agreement after exactly 100 negotiation iterations. Having an equal utility value at iteration $\iota=85$ does not terminate the negotiation, since the VPP provides an offer package with selling $8385 \mathrm{~kW}$ of electric power for $0.0227 \$ / \mathrm{kWh}$ whereas the aggregator returns another offer package with buying $4738 \mathrm{~kW}$ of electric power for $0.0212 \$ / \mathrm{kWh}$. Fig. 6(c) experiences the same setting as Fig. 6(b) does, where negotiators reach an agreement after 71 negotiation iterations. Reasons for having unequal number of buyer and seller prosumers are the absence of PV generation (when there is no sun), presence of BESSs with average state of charge of $48 \%$, and all refrigerators, 23 dishwashers, 12 newly arrived electric vehicles, and all air conditioners in operation.

Fig. 7 demonstrates how increasing the number of prosumers influences the average computation time and the negotiation convergence at each time interval. It proves that the proposed framework is scalable, since in practice, as described in Section IV-B, it will be executed in a fully distributed manner. In that case, the NSGA-III for each prosumer (or the aggregator), would approximately take 0.6 second. To evaluate the practicality of the framework, we revise the framework to have parallel bilateral negotiations between prosumers and the aggregator (without VPP), enabling us to compare with the concept of the single bilateral negotiation introduced in this paper (with VPP). Table III compares these scenarios 

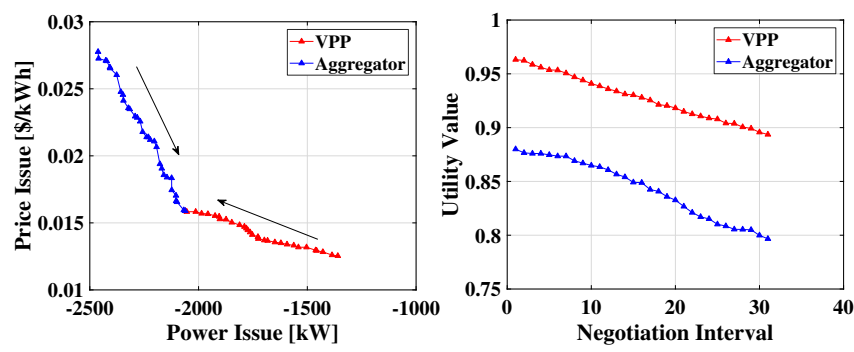

(a) 100 buyer prosumers (all equipped with no PVs and BESSs).
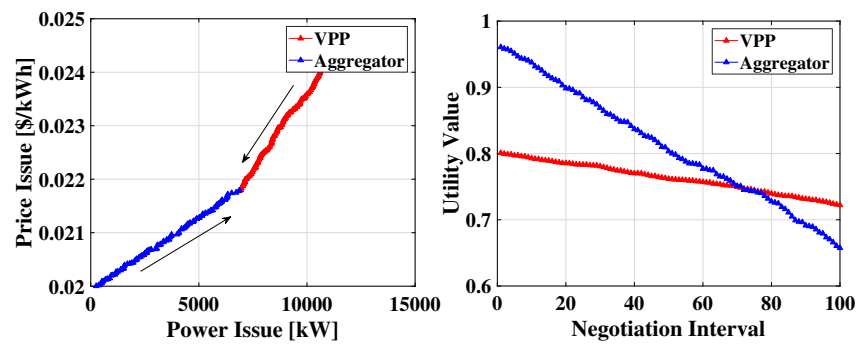

(b) 100 seller prosumers (all equipped with PVs and BESSs).
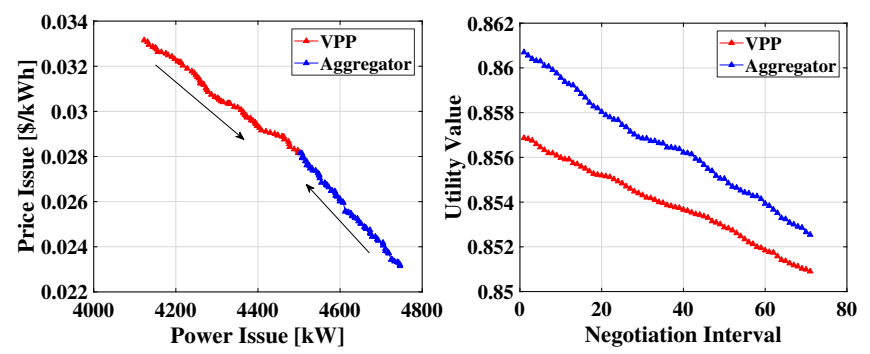

(c) 38 buyer and 62 seller prosumers (all equipped with PVs and BESSs).

Fig. 6. Offer package (left) and utility value concession (right).

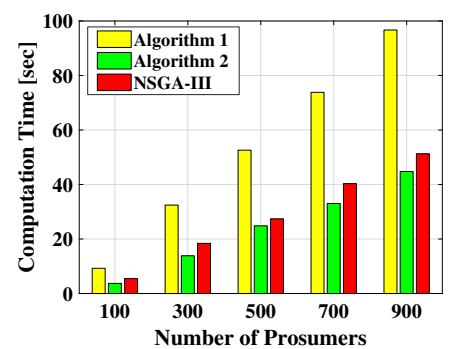

(a) Computation time.

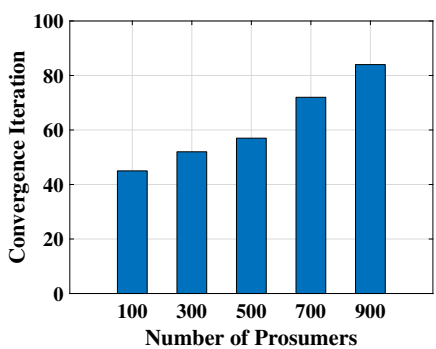

(b) Convergence iteration.
Fig. 7. Average computation time of the overall framework and negotiation convergence at each time interval based on different number of prosumers.

with respect to the average computation time of the overall framework and negotiation convergence at each time interval. For example with $m=900$ prosumers, having no VPP results, in average, $37.04 \%$ more computation time. The computation time of the NSGA-III is independent of the presence of the VPP. Furthermore, in this scenario, CPU and memory usages of the whole simulation are $79 \%$ and $42 \mathrm{~GB}$, respectively. However, these values for the computation device of each party, in the presence of the VPP, are $34.6 \%$ (of a single core $\mathrm{CPU}$ ) and $960 \mathrm{MB}$, respectively.

Table IV evaluates the assessment metrics with respect to different number of prosumers. As more prosumers are involved, the VPP has more opportunities in utilizing prosumers'
TABLE III

AVERAGE COMPUTATION TIME AND NEGOTIATION CONVERGENCE WITH RESPECT TO THE PRESENCE OF THE VPP.

\begin{tabular}{|c|c|c|c|c|c|c|c|}
\hline \multirow[b]{3}{*}{$m$} & \multicolumn{5}{|c|}{ Average computation time at each time interval [sec] } & \multirow{2}{*}{\multicolumn{2}{|c|}{$\begin{array}{l}\text { Average convergence iteration } \\
\text { at each time interval }\end{array}$}} \\
\hline & \multicolumn{2}{|c|}{ Overall } & \multicolumn{2}{|c|}{ Negotiation } & \multirow{2}{*}{$\begin{array}{c}\text { NSGA-III } \\
\text { w/ or wo/ VPP }\end{array}$} & & \\
\hline & $\mathrm{w}^{*} / \mathrm{VPP}$ & $\mathrm{wo}^{\dagger} / \mathrm{VPP}$ & $\mathrm{w} / \mathrm{VPP}$ & wo/ VPP & & $\mathrm{w} / \mathrm{VPP}$ & wo/ VPP \\
\hline 100 & 9.25 & 15.10 & 3.72 & 5.75 & 5.48 & 45 & 58 \\
\hline 300 & 32.44 & 52.96 & 13.85 & 21.42 & 18.40 & 52 & 63 \\
\hline 500 & 52.59 & 85.85 & 24.84 & 38.42 & 27.40 & 57 & 73 \\
\hline 700 & 73.82 & 120.51 & 33.03 & 51.10 & 40.33 & 72 & 89 \\
\hline 900 & 96.69 & 157.83 & 44.78 & 69.27 & 51.29 & 84 & 98 \\
\hline
\end{tabular}

flexibilities enabling it to: i) decrease the delay in satisfying load demands of appliances in average, ii) increase the PCB, and iii) increase the PDR. Increase in SLR and SSR also depends on the generation profiles of PVs in different weather conditions and the BESS capacities, and decrease in FUR.

TABLE IV

FRAMEWORK EVALUATION WITH DIFFERENT NUMBER OF PROSUMERS.

\begin{tabular}{cccccccc}
\hline$m$ & PDR (\%) & PAR & AOD (hrs) & FUR (\%) & PCB (\%) & SLR (\%) & SSR (\%) \\
\hline 100 & 15.19 & 2.76 & 3.30 & 42.00 & 65.40 & 10.10 & 14.03 \\
300 & 25.90 & 2.23 & 2.57 & 37.39 & 99.34 & 12.47 & 21.29 \\
500 & 32.19 & 2.13 & 2.29 & 31.91 & 147.97 & 15.08 & 32.51 \\
700 & 34.78 & 2.37 & 1.43 & 23.12 & 179.49 & 19.17 & 47.46 \\
900 & 38.46 & 2.01 & 1.13 & 18.75 & 209.47 & 24.45 & 51.21 \\
\hline
\end{tabular}

Table $\mathrm{V}$ evaluates to which extent the random distribution of PVs and BESSs influences the values of metrics. Compared to the setting, where all prosumers own PVs and BESSs (see the first row in Table IV), here, the grid experience lower PDR since the amount of flexibility is restricted. Decrease in AOD and FUR (due to limited flexibility) increases SLR and SSR (desire to increase the comfort), since the VPP cooperates with the aggregator to increase the PDR and PCB.

TABLE V

FRAMEWORK EVALUATION IN THE PRESENCE OF PVS AND BESSS.

\begin{tabular}{lccccccc}
\hline$\forall \rho_{i} \in \mathcal{P}$ & PDR $(\%)$ & PAR & AOD (hrs) & FUR (\%) & PCB (\%) & SLR (\%) & SSR (\%) \\
\hline Only PV & 11.43 & 2.95 & 1.56 & 28.18 & 46.73 & 20.16 & 20.16 \\
Only BESS & 33.29 & 2.08 & 1.20 & 11.67 & 35.46 & 0.83 & 0.00 \\
Random & 16.32 & 2.60 & 1.25 & 12.91 & 39.97 & 6.06 & 6.51 \\
\hline
\end{tabular}

Table VI analyzes the behavior of framework in different weather conditions. Fluctuations in the PV generation limit the VPP, in terms of available flexibility, in the negotiation.

TABLE VI

FRAMEWORK EVALUATION WITH DIFFERENT WEATHER CONDITIONS.

\begin{tabular}{llllllll}
\hline Weather & PDR (\%) & PAR & AOD (hrs) & FUR (\%) & PCB (\%) & SLR (\%) & SSR (\%) \\
\hline Sunny & 15.19 & 2.76 & 3.30 & 42.00 & 65.40 & 10.10 & 14.03 \\
Cloudy & 09.42 & 2.99 & 1.33 & 14.04 & 37.78 & 07.15 & 13.30 \\
\hline
\end{tabular}

Table VII evaluates the assessment metrics with respect to the various BESS capacities (in addition to the base BESS capacity). High BESS capacity provides prosumers with: i) more flexibility in storing energy, ii) lower AOD, and iii) higher PCB by selling more to the grid. The VPP, by such increase in the capacity, is able to provide the grid with more flexibility, which in turn, results in having higher PDR. 
TABLE VII

FRAMEWORK EVALUATION WITH VARIOUS BESSS CAPACITIES.

\begin{tabular}{llllllll}
\hline$B_{i}^{c a p}, \forall \rho_{i} \in \mathcal{P}$ & PDR (\%) & PAR & AOD (hrs) & FUR (\%) & PCB (\%) & SLR (\%) & SSR (\%) \\
\hline $13.2 \mathrm{kWh}$ & 15.19 & 2.76 & 3.30 & 42.00 & 65.40 & 10.10 & 14.03 \\
$26.4 \mathrm{kWh}$ & 24.36 & 2.38 & 2.00 & 34.68 & 102.72 & 14.84 & 14.66 \\
$39.6 \mathrm{kWh}$ & 39.62 & 1.98 & 0.58 & 25.36 & 165.57 & 18.12 & 14.34 \\
\hline
\end{tabular}

Table VIII evaluates the assessment metrics based on different appliance sets of 100 prosumers. A non-shiftable refrigerator yields no PDR and delay. Adding more shiftable appliances help prosumers provide the VPP with more consumption flexibility. Such increase has a direct correlation with the AOD and $\mathrm{PCB}$, where prosumers benefit more whereas waiting for a longer time to ensure have their appliances completed the operation. Simulation results confirm that a shiftable appliance contributes to the PDR in the grid and to the prosumer's PCB with averagely $0.1 \%$ and $0.37 \%$, respectively.

TABLE VIII

FRAMEWORK EVALUATION WITH DIFFERENT SETS OF APPLIANCES

\begin{tabular}{lccccccc}
\hline $\mathcal{A P} \mathcal{P}_{i}, \forall \rho_{i} \in \mathcal{P}$ & PDR (\%) & PAR & AOD (hrs) & FUR (\%) & PCB (\%) & SLR (\%) & SSR (\%) \\
\hline$\{$ RG $\}$ & 0 & 3.15 & 0.00 & 0.00 & 6.10 & 2.94 & 16.58 \\
$\{$ RG, WM $\}$ & 03.42 & 3.11 & 0.14 & 2.39 & 10.68 & 3.32 & 16.35 \\
$\{$ RG, WM, LD & 09.22 & 3.01 & 0.58 & 13.19 & 26.98 & 6.20 & 15.39 \\
$\{$ RG, WM, LD, DW $\}$ & 11.63 & 2.92 & 1.37 & 20.90 & 34.33 & 8.06 & 15.14 \\
$\{$ RG, WM, LD, DW, EV $\}$ & 13.24 & 2.85 & 2.26 & 30.27 & 49.88 & 9.44 & 12.24 \\
$\{$ RG, WM, LD, DW, EV, AC $\}$ & 15.19 & 2.76 & 3.30 & 42.00 & 65.40 & 10.10 & 14.03 \\
\hline
\end{tabular}

Table IX makes a qualitative (system architecture) and quantitative (simulation results) comparative analysis between a number of relevant works and the proposed framework. Simulation results are captured/calculated directly from the references. However, some fail to provide adequate performance analysis considering the assessment metrics selected for comparison. The comparison validates that the developed framework outperforms the similar approaches in the literature considering the size of simulated system.

\section{CONClusions AND Future Work}

This paper proposes a non-cooperative framework for coordinating a neighborhood of distributed prosumers, which possess smart appliances, photovoltaics, and battery energy storage systems. Prosumers intend to maximize their comfort level and profit at the same time whereas the aggregator aims at maximizing its profit and minimizing the grid purchase, simultaneously. Prosumers are able to schedule their appliances and share surplus power with the grid. The aggregator controls the power matching over time. As a result, the framework faces two multi-objective mixed integer nonlinear programming models for prosumers and the aggregator.

To relieve the burden of parallel bilateral communications, between prosumers and the aggregator, a virtual power plant communicates with an aggregator on behalf of prosumers to take advantage of their consumption, generation, and storage flexibilities. This paper employs an efficient negotiation approach, in which the virtual power plant and the aggregator negotiate on packaged power and price offers subject to having no knowledge about each other's preferences and utility functions. This approach utilizes an alternating offer package production protocol and a reactive utility value concession strat- egy, where negotiators have no incentive to deliberately stop conceding while the zone of agreement remains nonempty.

Future work will focus on incorporating industrial and commercial prosumers, and adding a negotiation level between various aggregators.

\section{REFERENCES}

[1] D. Niyato, Q. Dong, P. Wang, and E. Hossain, "Optimizations of Power Consumption and Supply in the Smart Grid: Analysis of the Impact of Data Communication Reliability," IEEE Trans. Smart Grid, vol. 4, no. 1, pp. 21-35, 2013.

[2] Z. Guan, J. Li, L. Zhu, Z. Zhang, X. Du, and M. Guizani, "Toward Delay-Tolerant Flexible Data Access Control for Smart Grid With Renewable Energy Resources," IEEE Trans. Industrial Informatics, vol. 13, no. 6, pp. 3216-3225, 2017.

[3] S. M. Nosratabadi, R.-A. Hooshmand, and E. Gholipour, "A Comprehensive Review on Microgrid and Virtual Power Plant Concepts Employed for Distributed Energy Resources Scheduling in Power Systems," Renewable and Sustainable Energy Reviews, vol. 67, pp. 341-363, 2017.

[4] A. Mohammadi, M. Mehrtash, and A. Kargarian, "Diagonal Quadratic Approximation for Decentralized Collaborative TSO+DSO Optimal Power Flow," IEEE Trans. on Smart Grid, 2018.

[5] N. G. Paterakis, O. Erdinç, I. N. Pappi, A. G. Bakirtzis, and J. P. Catalão, "Coordinated Operation of a Neighborhood of Smart Households Comprising Electric Vehicles, Energy Storage and Distributed Generation," IEEE Trans. Smart Grid, vol. 7, no. 6, pp. 2736-2747, 2016.

[6] K. Worthmann, C. M. Kellett, P. Braun, L. Grüne, and S. R. Weller, "Distributed and Decentralized Control of Residential Energy Systems Incorporating Battery Storage," IEEE Trans. Smart Grid, vol. 6, no. 4, pp. 1914-1923, 2015.

[7] N. Liu, X. Yu, C. Wang, C. Li, L. Ma, and J. Lei, "Energy-Sharing Model With Price-Based Demand Response for Microgrids of Peer-toPeer Prosumers," IEEE Trans. Power Systems, vol. 32, no. 5, pp. 35693583, 2017.

[8] T. AlSkaif, M. G. Zapata, and B. Bellalta, "A Reputation-Based Centralized Energy Allocation Mechanism for Microgrids," in IEEE International Conf. on Smart Grid Communications (SmartGridComm), 2015, pp. 416-421.

[9] A. G. Azar and R. H. Jacobsen, "Agent-Based Charging Scheduling of Electric Vehicles," in IEEE Online Conf. on Green Communications (OnlineGreenComm), 2016, pp. 64-69.

[10] _ , "Appliance Scheduling Optimization for Demand Response," International Journal on Advances in Intelligent Systems, vol. 9, no. $1 \& 2$, pp. 50-64, 2016.

[11] A. G. Azar, M. Afsharchi, M. Davoodi, and B. S. Bigham, "A MultiObjective Market-Driven Framework for Power Matching in the Smart Grid," Engineering Applications of Artificial Intelligence, vol. 70, pp. 199-215, 2018.

[12] T. AlSkaif, A. C. Luna, M. G. Zapata, J. M. Guerrero, and B. Bellalta, "Reputation-Based Joint Scheduling of Households Appliances and Storage in a Microgrid With a Shared Battery," Energy and Buildings, vol. 138 , pp. 228-239, 2017.

[13] T. AlSkaif, M. G. Zapata, B. Bellalta, and A. Nilsson, "A Distributed Power Sharing Framework Among Households in Microgrids: A Repeated Game Approach," Computing, vol. 99, no. 1, pp. 23-37, 2017.

[14] J. Kang, R. Yu, X. Huang, S. Maharjan, Y. Zhang, and E. Hossain, "Enabling Localized Peer-to-Peer Electricity Trading among Plug-In Hybrid Electric Vehicles using Consortium Blockchains," IEEE Trans. Industrial Informatics, vol. 13, no. 6, pp. 3154-3164, 2017.

[15] I. Atzeni, L. G. Ordóñez, G. Scutari, D. P. Palomar, and J. R. Fonollosa, "Noncooperative and Cooperative Optimization of Distributed Energy Generation and Storage in the Demand-Side of the Smart Grid," IEEE Trans. Signal Processing, vol. 61, no. 10, pp. 2454-2472, 2013.

[16] Y. Zhou, S. Ci, H. Li, and Y. Yang, "A New Framework for Peer-toPeer Energy Sharing and Coordination in the Energy Internet," in IEEE International Conf. on Communications (ICC), 2017, pp. 1-6.

[17] Q. D. La, Y. W. E. Chan, and B.-H. Soong, "Power Management of Intelligent Buildings Facilitated by Smart Grid: A Market Approach," IEEE Trans. Smart Grid, vol. 7, no. 3, pp. 1389-1400, 2016.

[18] K. Rahbar, C. C. Chai, and R. Zhang, "Energy Cooperation Optimization in Microgrids with Renewable Energy Integration," IEEE Trans. Smart Grid, 2016 
TABLE IX

QUALITATIVE AND QUANTITATIVE COMPARATIVE ANALYSIS BETWEEN A NUMBER OF RELEVANT WORKS AND THE PROPOSED FRAMEWORK.

\begin{tabular}{|c|c|c|c|c|c|c|c|c|c|c|c|}
\hline \multirow{2}{*}{ Reference } & \multirow{2}{*}{ High-level description } & \multicolumn{6}{|c|}{ System architecture } & \multicolumn{4}{|c|}{ Simulation analysis } \\
\hline & & $\begin{array}{c}\text { Control } \\
\text { mechanism }\end{array}$ & $\begin{array}{l}\text { Optimization } \\
\text { model }\end{array}$ & Objective(s) & $\begin{array}{l}\text { Flexibility per } \\
\text { prosumer }\end{array}$ & Negotiation & Scalable & $\begin{array}{l}\text { Simulation scenario } \\
\text { (System Size) }\end{array}$ & PDR (\%) & PCB $(\%)$ & $\begin{array}{c}\text { Computation } \\
\text { time (sec.) }\end{array}$ \\
\hline N. Paterakis et al. [5] & $\begin{array}{l}\text { A formulation for the simultaneous } \\
\text { operation of prosumers via a two- } \\
\text { step coordination strategy consider- } \\
\text { ing bi-directional power flow and } \\
\text { hourly-varying pricing scheme }\end{array}$ & Centralized & MILP & $\begin{array}{l}\text { A single objective of } \\
\text { minimizing the total en- } \\
\text { ergy procurement cost }\end{array}$ & $\begin{array}{l}\text { Consumption by ap- } \\
\text { pliances, generation } \\
\text { by the PV, and stor- } \\
\text { age by the BESS }\end{array}$ & No & No & $\begin{array}{l}3 \text { households, each } \\
\text { equipped with } 3 \\
\text { appliances, a PV, and } \\
\text { a BESS }\end{array}$ & 26 & 1 & 24 \\
\hline K. Worthmann et al. $\overline{[} \overline{6}^{-}$ & $\begin{array}{l}\text { A control methodology for dis- } \\
\text { tributed RESs to mitigate difficulty } \\
\text { in supply-demand balance relying on } \\
\text { load and generation forecasting }\end{array}$ & $\bar{C}^{-} \bar{n}^{-}{ }^{-} \overline{-}^{-}{ }^{-}$ & $\begin{array}{c}\text { (E-MPC) } \\
\text { (E-MP }\end{array}$ & $\begin{array}{l}\text { A single objective of } \\
\text { flattening the aggregate } \\
\text { power usage of the RESs }\end{array}$ & $\begin{array}{l}\text { Consumption by ap- } \\
\text { pliances, and storage } \\
\text { by the BESS }\end{array}$ & ${ }^{-} \overline{N o}^{-}$ & $\overline{\mathrm{No}}^{-}$ & $\begin{array}{l}3-\bar{R} \overline{E S},{ }^{-} \text {each }^{-} \\
\text {equipped with a } \\
\text { BESS }\end{array}$ & ${ }^{-} 1 \overline{9} . \overline{1} 0^{-}$ & & $\bar{H}_{\text {High }}{ }^{--}$ \\
\hline 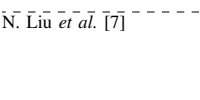 & $\begin{array}{l}\text { An day-aheà energy-sharing model } \\
\text { with dynamical price-based demand } \\
\text { response for peer-to-peer neighbor- } \\
\text { ing PV prosumers }\end{array}$ & Céntrāizèd $^{-}$ & $\begin{array}{c}-{ }^{-} \overline{C o n v e x}^{-} \\
\text {(Bi-level) }\end{array}$ & 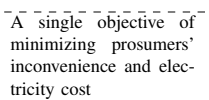 & $\begin{array}{l}\text { Generation }{ }^{-} \overline{b y}^{-}{ }^{-} \overline{t h e}^{-} \\
\text {PV }\end{array}$ & ${ }^{-} \overline{N o}^{-}$ & $\mathrm{No}^{-}$ & $\begin{array}{l}5^{-} \text {buildings, } \text { each }^{-} \\
\text {equipped with a PV } \\
\text { system }\end{array}$ & & $-\overline{5} . \overline{01}{ }^{-}$ & $\overline{2} \overline{00^{--}-}$ \\
\hline T. Àls̄kaif $\overline{e t}$ al. $\overline{[}[\overline{1}]^{-}$ & $\begin{array}{l}\text { A reputation-based energy manage- } \\
\text { ment system for prosumers to con- } \\
\text { trol the reallocation of available en- } \\
\text { ergy in the shared storage unit }\end{array}$ & $\overline{\text { Distributed }}^{-}$ & $\bar{M} \bar{M} \overline{L P}^{-}-$ & $\begin{array}{l}\mathrm{A}^{-} \text {single objective of } \\
\text { minimizing the amount } \\
\text { and price of energy ab- } \\
\text { sorbed from the grid }\end{array}$ & $\begin{array}{l}\text { Consumption by ap- } \\
\text { pliances and genera- } \\
\text { tion by the PV }\end{array}$ & $\mathrm{No}^{-}$ & $\overline{\mathrm{No}}^{-}$ & $\begin{array}{l}\overline{\mathrm{A}} \text { single } \overline{\mathrm{BE}} \overline{\mathrm{S} S} \text { shared } \\
\text { with } 3 \text { households, } \\
\text { each equipped with } 4 \\
\text { appliances and a PV }\end{array}$ & $\overline{11.5}-$ & $-6 \overline{8}^{-}$ & $-1 \overline{0}^{---}$ \\
\hline I. Atzeni $\overline{e t}$ al. $\overline{[}\left[\overline{15} \bar{c}^{-}\right.$ & $\begin{array}{l}\text { A day-ahead demand-side manage- } \\
\text { ment mechanism based on a general } \\
\text { dynamic energy pricing model regu- } \\
\text { lated via an independent central unit } \\
\text { preserving the prosumers' privacy }\end{array}$ & $\overline{D i s t r i b u t e d}^{-}$ & ${ }^{-} \overline{\mathrm{NLP}} \overline{\mathrm{P}}^{--}$ & $\begin{array}{l}\text { A single objective of } \\
\text { reducing (accumulated) } \\
\text { monetary expenses for } \\
\text { each (all) prosumer(s) }\end{array}$ & $\begin{array}{l}\text { Consumption by ap- } \\
\text { pliances, generation } \\
\text { possibility, and stor- } \\
\text { age by the BESS }\end{array}$ & $\begin{array}{l}-\bar{Y}^{-}- \\
\text {(Nash) }\end{array}$ & $\overline{\text { Yes }}^{-}$ & $\begin{array}{l}\text { with generation pos- } \\
\text { sibility and equipped } \\
\text { with a set of appli- } \\
\text { ances and a BESS }\end{array}$ & $-\overline{12.6}-$ & $2 \overline{0} . \overline{7} \overline{6}$ & -- \\
\hline Y. Žnou et âl. $[\overline{1} \overline{6}]^{-}$ & $\begin{array}{l}\text { A framework for the time-sioted } \\
\text { peer-to-peer energy sharing and co- } \\
\text { ordination aiming at achieving flex- } \\
\text { ible and efficient distributed energy } \\
\text { management and control }\end{array}$ & $\overline{\text { Distributed }}^{-}$ & $\begin{array}{l}{ }^{-} \bar{C}^{-}-\overline{n^{\prime}}-{ }^{-} \\
\text {(ADMM) }\end{array}$ & 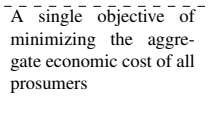 & $\begin{array}{l}\text { Consumption by ap- } \\
\text { pliances, generation, } \\
\text { by e.g., the PV, and } \\
\text { storage by the BESS }\end{array}$ & $\mathrm{No}^{-}$ & YYes $^{-}$ & $\begin{array}{l}36 \text { prosumers, each } \\
\text { equipped with a set of } \\
\text { appliances, a PV and a } \\
\text { BESS }\end{array}$ & $\overline{2} \overline{0} . \overline{7} \overline{-}^{-}$ & $\overline{2} \overline{7}^{-}$ & $=$ \\
\hline 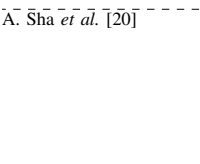 & $\begin{array}{l}\text { A strategy for optimizing distributed } \\
\text { energy exchange considering pro- } \\
\text { sumers involvement, energy loss } \\
\text { of delivery, network topology, and } \\
\text { physical constraints of distribution } \\
\text { networks approached by a graph } \\
\text { theory-based algorithm }\end{array}$ & $\bar{D}^{\overline{s i s}_{\text {stributed }}}{ }^{-}$ & $-\overline{\mathrm{L}} \overline{\mathrm{P}}-\overline{-}$ & $\begin{array}{l}\text { A single objective of } \\
\text { minimizing the cost of } \\
\text { buying energy and the } \\
\text { loss in energy delivery }\end{array}$ & $\begin{array}{l}\text { Generation by either } \\
\text { a small wind turbine } \\
\text { or PV }\end{array}$ & ${ }^{-} \overline{N o}^{--}$ & $\overline{\mathrm{No}}^{-}$ & $\begin{array}{l}1 \overline{3} \text { prosumers, each } \\
\text { equipped with either a } \\
\text { small wind turbine or } \\
\text { PV }\end{array}$ & $-\overline{97.5}{ }^{-}$ & $\overline{6}^{-}$ & $\overline{-}$ \\
\hline This work & $\begin{array}{l}\text { A scalable non-cooperative frame- } \\
\text { work for coordinating a neighbor- } \\
\text { hood of prosumers, equipped with } \\
\text { appliances, PVs, and BESSs, en- } \\
\text { gaged with a reactive bilateral multi- } \\
\text { issue negotiation approach subject to } \\
\text { sharing no private information }\end{array}$ & $\overline{\text { Distributed }}^{-}$ & ${ }^{-} \overline{\mathrm{M}} \overline{\mathrm{O}}-\overline{\mathrm{M}} \overline{\mathrm{INL}} \overline{\mathrm{P}}^{-}$ & $\begin{array}{l}\text { Two objectives of maxi- } \\
\text { mizing the comfort level } \\
\text { and profit for each pro- } \\
\text { sumer as well as max- } \\
\text { imizing the profit and } \\
\text { minimizing the grid pur- } \\
\text { chase for the aggregator }\end{array}$ & $\begin{array}{l}\text { Consumption by ap- } \\
\text { pliances, generation } \\
\text { by the PV, and stor- } \\
\text { age by the BESS }\end{array}$ & $\overline{Y e s}$ & $\bar{Y}^{-} \mathrm{es}^{-1}$ & $\begin{array}{l}900 \text { prosumers, each } \\
\text { equipped with } 6 \text { ap- } \\
\text { pliances, a PV, and a } \\
\text { BESS }\end{array}$ & $\overline{3} \overline{8} . \overline{4} \bar{\sigma}^{-}$ & $\overline{20} \overline{0} \cdot \overline{4}$ & $\overline{96.69} \overline{9}^{--}$ \\
\hline
\end{tabular}
Abbreviations for the optimization models denote: MILP: Mixed Integer Linear Programming; LP: Linear Programming; E-MPC: Economic Model Predictive Control; NLP: Nonlinear Programming; ADMM: Alternating Direction
Method of Multipliers; and MO-MINLP: Multi-Objective Mixed Integer Nonlinear Programming. Furthermore, some references fail to provide adequate performance analysis considering the assessment metrics selected for comparison.

[19] T. Taniguchi, K. Kawasaki, Y. Fukui, T. Takata, and S. Yano, "Automated Linear Function Submission-Based Double Auction as Bottom-Up RealTime Pricing in a Regional Prosumers' Electricity Network," Energies, vol. 8, no. 7, pp. 7381-7406, 2015.

[20] A. Sha and M. Aiello, "A Novel Strategy for Optimising Decentralised Energy Exchange for Prosumers," Energies, vol. 9, no. 7, p. 554, 2016.

[21] R. Zafar, A. Mahmood, S. Razzaq, W. Ali, U. Naeem, and K. Shehzad, "Prosumer based energy management and sharing in smart grid," Renewable and Sustainable Energy Reviews (In Press), 2017.

[22] X. Ayón, J. Gruber, B. Hayes, J. Usaola, and M. Prodanović, “An Optimal Day-Ahead Load Scheduling Approach Based on the Flexibility of Aggregate Demands," Applied Energy, vol. 198, pp. 1-11, 2017.

[23] K. Deb and H. Jain, "An Evolutionary Many-Objective Optimization Algorithm Using Reference-Point-Based Nondominated Sorting Approach, Part I: Solving Problems With Box Constraints," IEEE Trans. Evolutionary Computation, vol. 18, no. 4, pp. 577-601, 2014.

[24] R. Zheng, T. Dai, K. Sycara, and N. Chakraborty, "Automated Multilateral Negotiation on Multiple Issues with Private Information," INFORMS Journal on Computing, vol. 28, no. 4, pp. 612-628, 2016.

[25] A. Soares, Á. Gomes, and C. H. Antunes, "Categorization of Residential Electricity Consumption as a Basis for the Assessment of the Impacts of Demand Response Actions," Renewable and Sustainable Energy Reviews, vol. 30, pp. 490-503, 2014.

[26] A. G. Azar, "SALSA: A Formal Hierarchical Optimization Framework for Smart Grid," PhD Thesis, 2017.

[27] G. d. O. e Silva and P. Hendrick, "Lead-Acid Batteries Coupled With Photovoltaics for Increased Electricity Self-Sufficiency in Households," Applied Energy, vol. 178, pp. 856-867, 2016.

[28] I. Atzeni, L. G. Ordóñez, G. Scutari, D. P. Palomar, and J. R. Fonollosa, "Demand-Side Management via Distributed Energy Generation and Storage Optimization," IEEE Trans. Smart Grid, vol. 4, no. 2, pp. 866876, 2013.

[29] Z. Xu, W. Su, Z. Hu, Y. Song, and H. Zhang, "A Hierarchical Framework for Coordinated Charging of Plug-in Electric Vehicles in China," IEEE Trans. Smart Grid, vol. 7, no. 1, pp. 428-438, 2016.

[30] B. Jie, T. Tsuji, and K. Uchida, "An Analysis of Market Mechanism and Bidding Strategy for Power Balancing Market Mixed by Conventional and Renewable Energy," in IEEE International Conf. on the European Energy Market (EEM), 2017, pp. 1-6.

[31] H. Jain and K. Deb, "An Evolutionary Many-Objective Optimization Algorithm Using Reference-Point Based Nondominated Sorting Approach, Part II: Handling Constraints and Extending to an Adaptive Approach," IEEE Trans. Evolutionary Computation, vol. 18, no. 4, pp. 602-622, 2014.

[32] D. M. Curry and C. H. Dagli, "Computational Complexity Measures for Many-Objective Optimization Problems," Procedia Computer Science, vol. 36 , pp. 185-191, 2014

[33] A. J. Hanson, "Hyperquadrics: Smoothly Deformable Shapes With Convex Polyhedral Bounds," Computer Vision, Graphics, and Image Processing, vol. 44, no. 2, pp. 191-210, 1988.

[34] A. Rubinstein, "Perfect Equilibrium in a Bargaining Model," Econometrica: Journal of the Econometric Society, pp. 97-109, 1982.

[35] G. Lai and K. Sycara, "A Generic Framework for Automated MultiAttribute Negotiation," Springer Group Decision and Negotiation, vol. 18 , no. 2, pp. 169-187, 2009.

[36] S. Boyd and L. Vandenberghe, Convex Optimization. Cambridge University Press, 2004

[37] H. A. Simon, "Rational Choice and the Structure of the Environment," Psychological Review, vol. 63, no. 2, p. 129, 1956.

[38] J. F. Nash Jr, "The Bargaining Problem," Econometrica: Journal of the Econometric Society, pp. 155-162, 1950.

[39] H. Nazaripouya, B. Wang, Y. Wang, P. Chu, H. Pota, and R. Gadh, "Univariate Time Series Prediction of Solar Power Using a Hybrid Wavelet-ARMA-NARX Prediction Method," in IEEE/PES Transmission and Distribution Conf. and Exposition (T\&D), 2016, pp. 1-5.

[40] M. Pipattanasomporn, M. Kuzlu, S. Rahman, and Y. Teklu, "Load Profiles of Selected Major Household Appliances and Their Demand Response Opportunities," IEEE Trans. Smart Grid, vol. 5, no. 2, pp. 742-750, 2014

[41] K. Qian, C. Zhou, M. Allan, and Y. Yuan, "Load Model for Prediction of Electric Vehicle Charging Demand," in IEEE International Conf. on Power System Technology, 2010, pp. 1-6.

[42] Nord Pool Spot, "https://www.nordpoolspot.com,” accessed: Nov. 2017. 